\title{
Baleen whale distribution and seasonal occurrence revealed by an ocean bottom seismometer network in the Western Indian Ocean
}

\author{
Richard Dréo $^{\mathrm{a}, *}$, Léa Bouffaut ${ }^{\mathrm{a}}$, Emmanuelle Leroy ${ }^{\mathrm{b}, \mathrm{c}}$, Guilhem Barruol ${ }^{\mathrm{d}}$, Flore Samaran ${ }^{\mathrm{b}}$ \\ a French Naval Academy Research Institute - BCRM CC600, 29240 Brest Cedex 9, France \\ b UMR CNRS 6285 Lab-STICC, ENSTA Bretagne, 29806 Brest, France \\ c University of Brest and CNRS, Laboratoire Geosciences Brest, IUEM, 29280 Plouzane, France \\ ${ }^{\mathrm{d}}$ Institut de Physique du Globe de Paris, Sorbonne Paris Cité, UMR 7154 CNRS, Paris, France
}

\section{A R T I C L E I N F O}

\section{Keywords:}

Passive acoustic monitoring

Ocean bottom seismometer

Baleen whale

Western Indian Ocean

Seasonal pattern

Distribution

Localization

Tracking

\begin{abstract}
A B S T R A C T
From the acoustic data acquired by the RHUM-RUM (Réunion Hotspot and Upper Mantle Réunions Unterer Mantel) Ocean Bottom Seismometer (OBS) network between October 2012 and November 2013, this study revealed baleen whale occurrence in the western Indian Ocean (IO). Low-frequency songs from three species (Antarctic Blue Whales, Pygmy Blue Whales and Fin Whales) as well as P-calls (or Spot-calls) from an unknown species were recorded on the dataset. The wide arrangement of the OBS network $(2000 \mathrm{~km} \times 2000 \mathrm{~km})$ provided valuable information to draw seasonal patterns of occurrence and distribution all over the area. These species occurred sympatrically in the western IO, at least during austral autumn months emphasizing the importance of this region for these populations. This data set helped to refine the knowledge on their spatio-temporal distribution and complete the picture built by previous studies. A tighter sub-network of 8 OBSs deployed on the South West Indian Ridge provided ideal inter-sensor spacing for whale tracking. We demonstrated the capability of such array of detecting and tracking the three different whale species up to $50 \mathrm{~km}$ and for several hours. As a result and to understand the effect of acoustic wave propagation, songs from the tracking were described at a close and remote distance of the sensor. This work could also help to understand the local behavior of these species during austral autumn months in this area of the western Indian Ocean.
\end{abstract}

\section{Introduction}

Baleen whales worldwide were driven close to extinction by commercial and illegal whaling in the 20th century. In 1979, the International Whaling Commission (IWC) created the Indian Ocean Whale Sanctuary (IOWS), the first area where all types of commercial whaling were banned (Chairman's, 1980). This sanctuary encompasses all the waters in the northern Indian Ocean (IO), including the Red Sea, from the east coast of Africa to $100^{\circ} \mathrm{E}$. The southern boundary is $55^{\circ} \mathrm{S}$ from $020^{\circ} \mathrm{E}$ to $130^{\circ} \mathrm{E}$. Open ocean waters cover the major part of the surface area of the IOWS and in such a large marine ecosystem it can be difficult to consistently monitor the presence of whale species over long time scales. Moreover, baleen whales are highly mobile migratory species for which understanding the conservation and management remains a challenge (Hyrenbach et al., 2000). The existence of baleen whales in the IO is well documented from whaling data; however, there is little information on the conservation status, broad-scale seasonal occurrence, or population identity of these animals (Leatherwood,
1986; Rice, 1998; De Boer et al., 2003; Branch et al., 2007). In the last two centuries, numerous expeditions and institutional efforts in the IO have greatly contributed to the knowledge of coastal and marine biodiversity. However, the status of knowledge is not uniform and gaps extend to several smaller taxa and to large parts of the shelf and deepsea ecosystems (Wafar et al., 2011). Recent knowledge on baleen whales in the IO relies on coastal areas visual sighting or telemetry. For instance, humpback whale (Megaptera novaengliae) population in the western IO have been studied in their breeding areas throughout the austral winter (Kiszka et al., 2010; Trudelle et al., 2016) and Pygmy Blue Whale (PBW) (Balaenoptera musculus brevicauda) population have been observed in the eastern IO in their feeding areas throughout the austral summer (Gill et al., 2011; Double et al., 2014). However, these methods are expensive, require dedicated manpower and are often poorly efficient, especially in deep waters (Mellinger et al., 2007). Nevertheless, the recent use of passive acoustic monitoring (PAM) increases our knowledge on the broad-scale seasonal occurrence and distribution of baleen whales in the IOWS. PAM is indeed a very

\footnotetext{
* Corresponding author.

E-mail addresses: richard.dreo@ecole-navale.fr (R. Dréo), lea.bouffaut@ecole-navale.fr (L. Bouffaut), emmanuelle.leroy@univ-brest.fr (E. Leroy), barruol@ipgp.fr (G. Barruol), flore.samaran@ensta-bretagne.fr (F. Samaran).
} 
efficient and relatively low cost tool to monitor baleen whales. Antarctic blue whales (ABW) (B. m. intermedia), PBW and Fin Whales (FW) (B. physalus) produce species specific song types with high source level and low frequencies, ideal for long-range detection in the bandwidth of our instruments $(0-50 \mathrm{~Hz})$. Recent acoustic studies describe their presence in the southern IO (Samaran et al., 2010a, 2013; Gavrilov and McCauley, 2013; Balcazar et al., 2015, 2017; Leroy et al., 2016) or in the northern IO (Stafford et al., 2004, 2011) and bring new pictures of their distribution and movements in deep-sea ecosystem. In this study, we propose to analyze acoustic records from Ocean Bottom Seismometers (OBSs) deployed during one year in the western Indian Ocean over a large area $\left(2000 \times 2000 \mathrm{~km}^{2}\right)$ around La Réunion in the frame of the RHUM-RUM (Réunion Hotspot and Upper Mantle Réunion's Unterer Mantel) experiment (RHUM-RUM,; Barruol and Sigloch, 2013). Previous studies have shown that hydrophones from OBSs can provide valuable data to monitor the low frequency calls of baleen whales. Data from OBSs have been used to track the movement of blue and FW (Rebull et al., 2006; Wilcock, 2012), to investigate potential behavioral responses to both anthropogenic and natural sound sources (Dunn and Hernandez, 2009) or to apply distance sampling for estimating the cetacean density (Harris et al., 2013). Here, we aim to identify lowfrequency baleen whale species that dwell in the area using their specific acoustic signature in the $[0-30] \mathrm{Hz}$ bandwidth. During the year of recording, seasonal distribution patterns are assessed at six sites across the RHUM-RUM network. Only the global population movements were considered, and not small scale calling individuals. We also use the opportunity of the presence of a small OBSs array deployed on the South West Indian Ridge (SWIR) to detect and track the call-generating whales in order to understand their local movements. Understanding occurrence and distribution of these endangered species at such a remote area provides significant informations on species range, migration, seasonality, which is essential for management and conservation. This study has important implications for recovery and conservation management by identifying new regions used by different baleen whale species.

\section{Experimental set up and material}

\subsection{RHUM-RUM network}

Data used in this work were recorded by the RHUM-RUM seismic network (RHUM-RUM; Barruol and Sigloch, 2013; Barruol et al., 2017) and are currently hosted at the RESIF French national seismic archive centre (Rhum-rum dataset; RESIF). This project is primary aimed at imaging the mantle structure beneath the SW Indian Ocean and the dynamics of La Réunion volcanic hotspot, but the seismic data have been shown to also provide valuable environmental information, such as their ability to monitor the ocean swell activity (Davy et al., 2014). The seismic network consisted of 57 Ocean Bottom Seismometers (OBSs) deployed on the ocean floor over an area of $2000 \times 2000 \mathrm{~km}^{2}$ (see Fig. 1) in the western IO (Lat. $16-34^{\circ} \mathrm{S}$, Long. $048-070^{\circ} \mathrm{E}$, immersion $[-5430 ;-2002] \mathrm{m}$ ), from October 2012 to November 2013. Each OBS was equipped with a three component seismometer and by either a hydrophone or a differential pressure gauge.

Six OBSs (black star circled in white on Fig. 1) from this large network were selected for their quality, location and sampling frequency (Table 1), to assess the seasonal occurrence of baleen whales (Section 4.2) during this period. These instruments are part of the French INSU (Institut national des sciences de l'Univers) national pool and were of the type LCPO2000-BBOBS, based on the Scripps Institution of Oceanography (SIO) "L-CHEAPO" design. Their frequency response and technical details are found in Stähler et al. (2016).

\subsection{An OBS sub-network on the SWIR}

In order to characterize the micro-seismicity (Schmid et al., 2017) associated to an active seamount located on the Southwest Indian Ridge (the extensive tectonic plate boundary between Africa and Antarctica), RHUM-RUM deployed a local and denser sub-array of 8 OBSs, sampling data at $100 \mathrm{~Hz}$. Those OBSs are part of the German OBS pool DEPAS (Deutscher Geräte-Pool fuür Amphibische Seismologie) and are of the LOBSTER type ("Long-term OBS for Tsunami and Earthquake Research"), the technical capabilities of which are detailed in Stähler et al. (2016).

This so-called SWIR array (Fig. 1 - zoomed section) covered an area of $70 \mathrm{~km} \times 40 \mathrm{~km}$ with depth varying from $2822 \mathrm{~m}$ at the top of the seamount to $5430 \mathrm{~m}$ in the trench with inter-station distances of the order of $20 \mathrm{~km}$. This refined discretization of the space provided a particularly good inter-sensor distance for multiple site observations of baleen whale calls and therefore for localization and tracking (Section 4.3).

\subsubsection{Clock drift estimation}

The SWIR array OBSs ran unfortunately out of batteries before the end of the experiment making impossible the synchronization of the internal clocks with the GPS signal immediately after the station recovery. This default therefore impeded to have a direct and accurate measurement of the absolute clock drift during the experiment and motivated an alternative way of retrieving indirectly the accurate timing at each station. This has been achieved using a multi-component noise cross-correlation Hable et al., 2018, that provides an accurate estimate of the clock drifts during the experiment and also demonstrated that the drifts were linearly accumulated over the period of recording, so that it was possible to post-synchronize the clocks and to get a precise timing of the data. Table 2 displays the estimated drifts for the SWIR array OBSs, and the corrections applied on each days of tracking. The maximum uncertainty on drift error estimates was $21.1 \mathrm{~ms}$ (RR44) over a hypothetical 365-day long deployment.

\subsubsection{OBS position uncertainties}

Once they were deployed, and depending on the water depth, OBSs sank freely from their own weights and took one to two hours to reach the seafloor. Although their final positions on the seabed were not exactly known, the GPS positions of the exact OBS deployment and recovery points were measured and showed distances between them generally smaller than $500 \mathrm{~m}$, resulting from the total drift induced by the water currents during both the descent and the ascent of the OBS. From such observation, seismologists considered that the position uncertainty are of the order of $200 \mathrm{~m}$.

\section{Acoustic data processing}

\subsection{Baleen whale acoustic signatures}

The presence of different species of baleen whales in the western IO was assessed through their songs, recorded by the OBSs. Their acoustic signatures were characterized using the Raven Pro v1.5 software (Cornell Lab of Ornithology, (Raven webpage,)). Blue whale songs answer to the same nomenclature (McDonald et al., 2006). The shortest component, denoted as a unit (or call unit), can either be pulsed or tonal. Units are bounded by any abrupt change e.g. pause, frequency or variation of the sweep rate. Calls are composed of units combined in organized sequences. These arrangements are species specific, as well as their Inter-Call Interval duration (ICI). Regularly repeated calls are denoted as series. Song describes the overall vocalizing behavior of a whale as a limited number of successive series. Series were separated by longer intervals corresponding to the breathing of the animal, denoted as Inter-Series Interval (ISI). For each vocal signature, units' characteristic frequencies, their duration, ICI and ISI were measured on good quality signals i.e. series with high Signal to Noise Ratio (SNR). Mean values and their standard errors (s.e.) were then calculated for each parameter. Basic characteristic features of those acoustic 


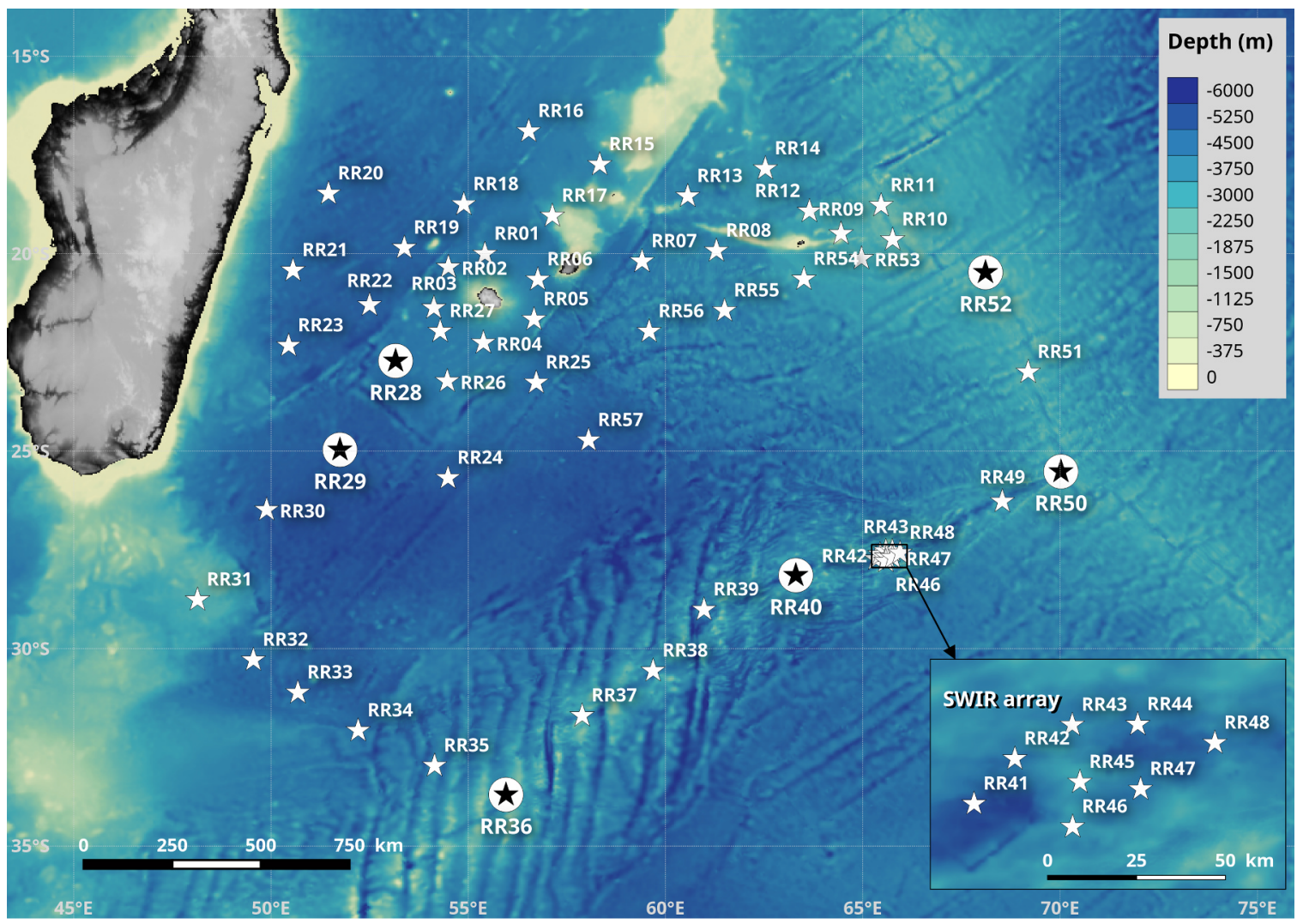

Fig. 1. RHUM-RUM network and the SWIR array Stähler et al. (2016); RHUM-RUM (). Black stars indicate the OBSs used for the whales seasonal pattern description and the SWIR array shown in the zoomed inset indicate OBSs used for local whales tracking.

Table 1

Latitude (Lat.), Longitude (Long.), Depth (z) and sampling frequency $f_{s}$ of the OBSs used for seasonal occurrence observation Stähler et al. (2016).

\begin{tabular}{lllll}
\hline OBS & Lat. & Long. & $z(\mathrm{~m})$ & $f_{s}(\mathrm{~Hz})$ \\
\hline RR28 & -22.7152 & 053.1594 & 4550 & 62 \\
RR29 & -24.9657 & 051.7488 & 4829 & 62 \\
RR36 & -33.7018 & 055.9578 & 3560 & 62 \\
RR40 & -28.1461 & 063.3020 & 4780 & 62 \\
RR50 & -25.5182 & 070.0222 & 4118 & 62 \\
RR52 & -20.4723 & 068.1094 & 2918 & 62 \\
\hline
\end{tabular}

signatures such as frequency, duration or energy were conventionally portrayed graphically as a spectrogram and its associated Power Density Spectrum (PSD). The informations conveyed by signal units were quantified using the product between the bandwidth and the duration of the signal, $B T$.

\subsection{Geographic and seasonal patterns of call presence}

The seasonality of the acoustic presence of the different baleen whales species were analyzed over the course of 13 months data, recorded on 6 different OBSs widely distributed over the RHUM-RUM network (section 2.1). Preliminary analysis of measurements in the SWIR array showed that the maximum detection range of ABW songs could be estimated close to $100 \mathrm{~km}$ on the most energetic calls (Section 4.3.1). Hence, we propose to consider OBSs observations of species calls as an indicator of their presence in an area, independently of the number of detected calls.

The proposed method consisted in detecting the presence of the predominant frequency of each species signature on a Long Term Spectrogram (LTS). LTS covered the whole recorded period with a Fast Fourier Transform (FFT) size set to 4096, and spectrum were averaged on a one-hour period. The main challenges were to distinguish each species specific frequency feature from the background noise generated by maritime traffic and seismic activity as well as separating overlapping call series from the different studied species, especially in low SNR contexts.

Table 2

Estimation of the OBS clock drifts (in ms) for a hypothetical 365-day long deployment, and for the three days of whale tracking (From Hable et al. 2018 see Section 4.3).

\begin{tabular}{|c|c|c|c|c|}
\hline OBS & ms/year (D 365) & 13th May (D 209) & 28th May (D 224) & 31st May (D 227) \\
\hline RR41 & $3202.1 \pm 16.3$ & $1833.6 \pm 9.3$ & $1965.1 \pm 10.0$ & $1991.5 \pm 10.1$ \\
\hline RR43 & $512.5 \pm 12.7$ & $293.4 \pm 7.2$ & $314.5 \pm 7.8$ & $318.7 \pm 7.9$ \\
\hline RR44 & $263.9 \pm 21.1$ & $151.1 \pm 12.1$ & $161.9 \pm 12.9$ & $164.1 \pm 13.1$ \\
\hline RR45 & $76.3 \pm 18.8$ & $43.7 \pm 10.8$ & $46.8 \pm 11.5$ & $47.4 \pm 11.7$ \\
\hline RR46 & $1424.2 \pm 14.7$ & $815.5 \pm 8.4$ & $874.0 \pm 9.0$ & $885.7 \pm 9.1$ \\
\hline RR47 & $2929.5 \pm 17.4$ & $1677.4 \pm 10.0$ & $1797.8 \pm 10.7$ & $1821.9 \pm 10.8$ \\
\hline RR48 & $938.8 \pm 19.2$ & $537.5 \pm 11.0$ & $576.1 \pm 11.8$ & $583.8 \pm 11.9$ \\
\hline
\end{tabular}


(a)

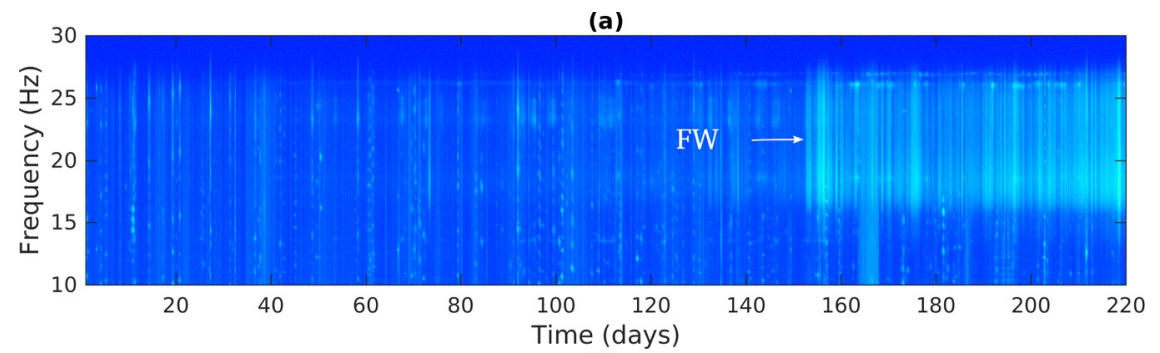

(b)

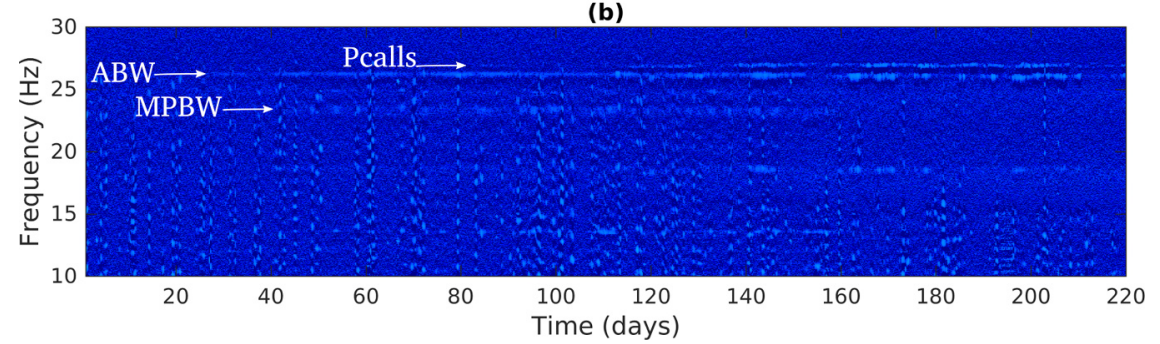

Fig. 2. Result of wide band reduction method, and improvement of P-calls, Z-calls and PBW calls over a 220 days period. (a) LTS focused in the 10-30 Hz band. The

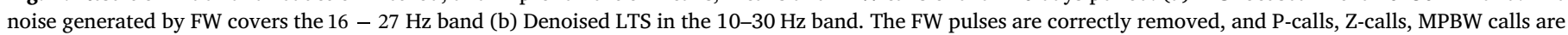
clearly visible.

Whale signatures presented two different aspects on a LTS: wide band e.g. FW pulses (Section 4.1.2) or narrow band e.g. ABW calls (Section Section 4.1.1), MPBW calls (Section 4.1.3) and P-calls (Section 4.1.4). A detection method, based on signal to noise ratio (SNR) estimate, was developed for both types, respectively in Sections 3.2.1 and 3.2 .2

\subsubsection{Wide band detection}

The FW $20 \mathrm{~Hz}$ pulses were wide band and highly energetic, hence they were clearly visible and quite easy to detect on a LTS (Fig. 2(a)). In this case, the SNR was defined as the ratio between the signal band's mean level and the noise band's mean level. To avoid overlap with other species songs, that could lead to false detection, the signal band was reduced to a representative part of the $20 \mathrm{~Hz}$ pulse (Table 3).

\subsubsection{Narrow band detection}

Narrow band signals were more affected by noise, and especially difficult to detect in presence of FW songs and earthquakes. The developed method aimed to reduce the impact of wide band noises to improve the SNR of narrow band signals, and particularly focusing on the most energetic tonal part of the calls.

The method's steps were:

1. Wide band noise estimation: a median filter was applied on LTS frequency dimension (the size of the filter was adapted to each song),

2. Wide band noise reduction: the step 1 estimation was removed from the LTS,

3. Normalization of the results,

4. Low signal enhancement: a log based function was applied to strengthen low amplitude signals. The result is the denoised LTS shown in Fig. 2(b),

5. SNR calculation: the mean level in the signal band and the mean

Table 3

Signal band and noise band frequency details for call detection in LTS.

\begin{tabular}{lll}
\hline Species/Voc. & Signal frequency band $(\mathrm{Hz})$ & Noise frequency band $(\mathrm{Hz})$ \\
\hline Z-calls & $25.85-26.4$ & $25.7-26.6$ \\
P-calls & $26.6-27.1$ & $26.4-27.4$ \\
PBW calls & $22.8-23.6$ & $22.3-24.2$ \\
FW pulse & $16.5-17.5$ & $10.0-15.0$ \\
\hline
\end{tabular}

level in the noise band were compared (Table 3). It is important to notice that the noise frequency bands were chosen to avoid overlap with the Signal band of other species calls.

Once calculated, the SNR was smoothed over three days to minimize the risk of false alarm due to the presence of ship tonal frequencies (during about 8-15 h). It was then compared to an empirical preset threshold to determine if there was a real detection in the signal band. Significant threshold overruns were considered as calling whale presence and were plotted over the course of the year for each call type.

A visual control of abnormal results was done to avoid false and missed detection. For instance, few false detections appeared due to the presence of ship tonal frequencies in the signal band during several days. Those quite flagrant cases were removed from the detection results. Furthermore, the three-day smoothing of the SNR could lead to missed detections particularly in the case of short vocalizing period. Those events were taken into account if they were not small scale calling individual.

\subsection{Whale tracking}

The small dimension of the SWIR array compared to the whole RHUM-RUM deployment (Fig. 1) and the $100 \mathrm{~Hz}$ sample frequency of the OBSs in this sub-network provided an ideal case for multi-sensor detection of ABW, FW and MPBW, and consequently for their respective localization. We used this unique opportunity to locate call-generating whales, with a Time Difference Of Arrival TDOA) based method, which is made possible by the accurate estimate of the OBSs clock drifts, and by a good OBS location on the seafloor.

\subsubsection{Environmental characteristics}

The so-called "SWIR array" was deployed on the mid-ocean ridge, a region of strong bathymetric variations and highly reflecting basaltic floor. This area morphology is dominated by a ENE-WSW trending rift valley, 5-6 km deep, in which has grown a large submarine volcano (under RR45) culminating at $3000 \mathrm{~m}$ depth beneath sea level (Fig. 3). The statistical sound speed profile (SSP) considered for this study (Fig. 4) corresponded to the May period in the SWIR array area. It was a typical Indian Ocean profile with a speed minimum at $1200 \mathrm{~m}$. Environment characteristics and wide distances between OBSs led to multipath propagation. Due to the tormented relief, there was no certainty that the direct ray could reach the OBSs (Fig. 4). Hence, the TOA 

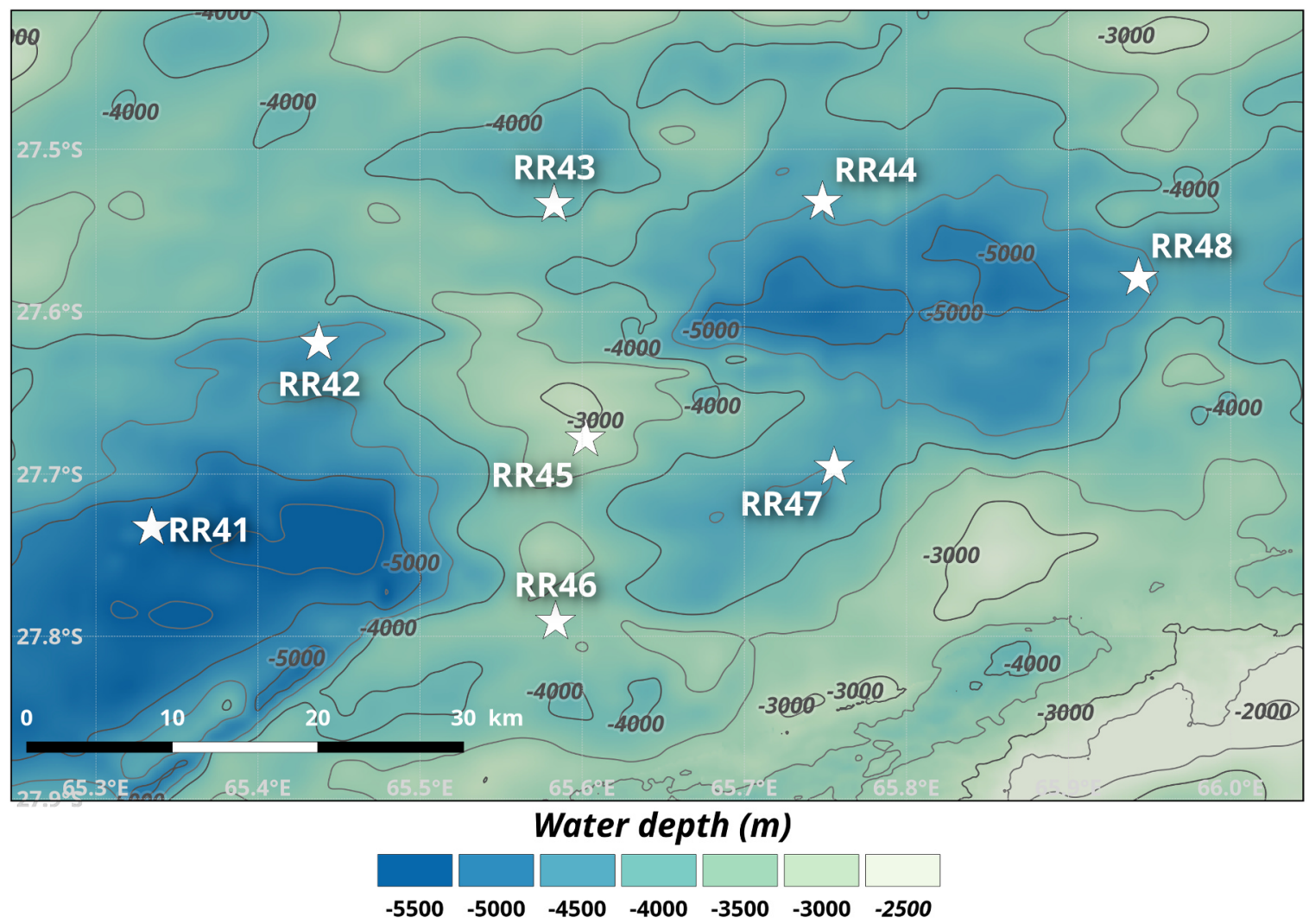

Fig. 3. Bathymetric map of the OBS sub-array on the South-West Indian Ridge (SWIR).

estimate based on the direct ray propagation, a constant depth and mean sound speed, was not consistent.

\subsubsection{Localization method considering environmental characteristics}

Fig. 5, describes the different steps of the method used to localize a singing whale in a region of complex bathymetry. The SWIR array area was first spatially discretized with a grid spacing of 0.01 degree in latitude and longitude (about $900 \mathrm{~m}$ ), each point of the matrix corresponding to a theoretical source $\left(\mathrm{S}_{\mathrm{th}}\right)$. To be as accurate as possible in this propagation context, the bathymetry profiles between each of the $20,000 \mathrm{~S}_{\text {th }}$ and the 7 OBSs were then systematically extracted. The theoretical Time Of Arrivals $\left(\mathrm{TOA}_{\mathrm{th}}\right.$ ) of whale calls were calculated for each $\mathrm{S}_{\text {th }}$-OBS path, using the ray tracing software BELLHOP (Ocean acoustics library,). The source depth was set to $20 \mathrm{~m}$, the frequency to
$20 \mathrm{~Hz}$, in accordance with big whale songs characteristics, and receiver depth to the considered OBS depth. As the height of the water column was over ten times the wave length $\left(\lambda_{20 \mathrm{~Hz}}=75 \mathrm{~m}\right)$, the ray propagating model was considered to be realistic (Ivansson, 2017). The theoretical Time Difference of Arrivals $\left(\mathrm{TDOA}_{\mathrm{th}}\right.$ ) of each $\mathrm{S}_{\mathrm{th}}$ were then calculated, considering only the first arriving ray provided by BELLHOP.

The Measured Time Of Arrivals $\left(\mathrm{TOA}_{\mathrm{m}}\right.$ ) of the pattern beginnings were handpicked on a spectrogram with a 128 samples FFT size and 90 $\%$ overlap. Then, Time Difference Of Arrival $\left(\mathrm{TDOA}_{\mathrm{m}}\right)$ were calculated. A similarity estimation between $\mathrm{TDOA}_{\mathrm{m}}$ and all the $\mathrm{TDOA}_{\text {th }}$ of the spatial matrix with a $\mathrm{L}_{2}$ norm, gave the probability of presence map of the source. The source location was obtained calculating the barycenter of the $5 \%$ best fitting $\mathrm{S}_{\text {th }}$.

Due to the multipath propagation, the received patterns (in the time
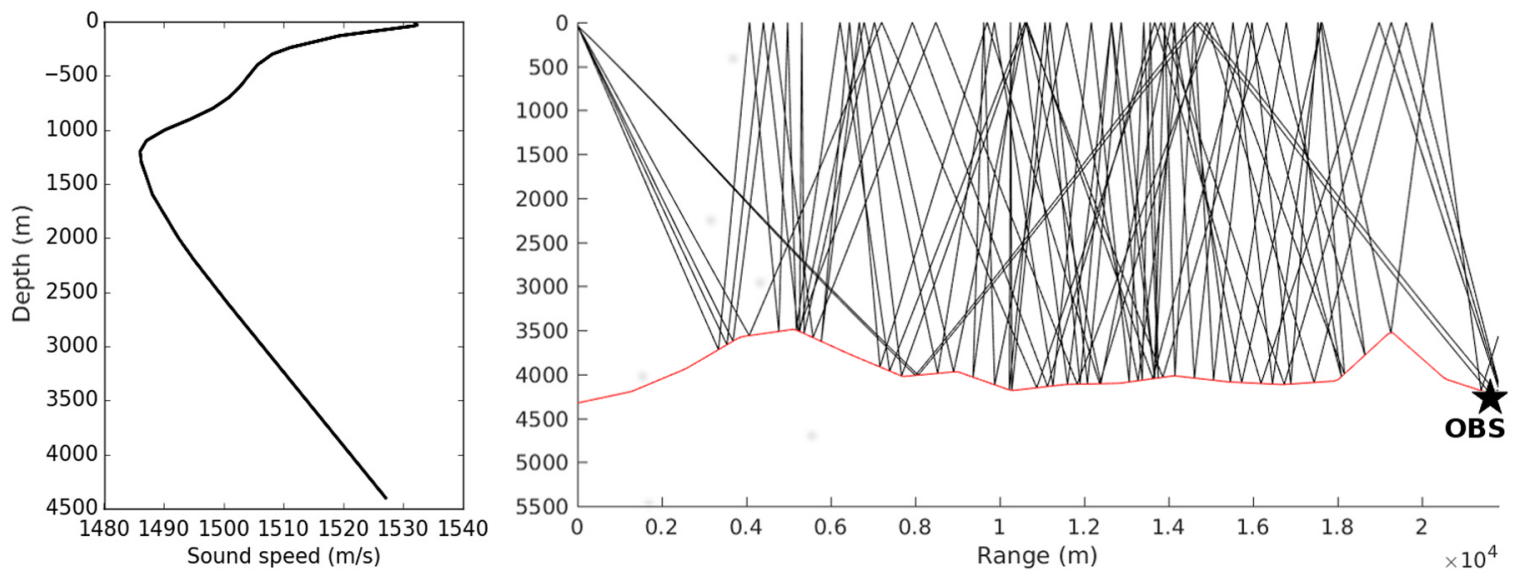

Fig. 4. Left: statistical SSP characteristic of May period in Indian Ocean. The profile was negative with a minimum at $1200 \mathrm{~m}$. Right: example of eigenrays tracing with no direct ray reaching the OBS (red star). 


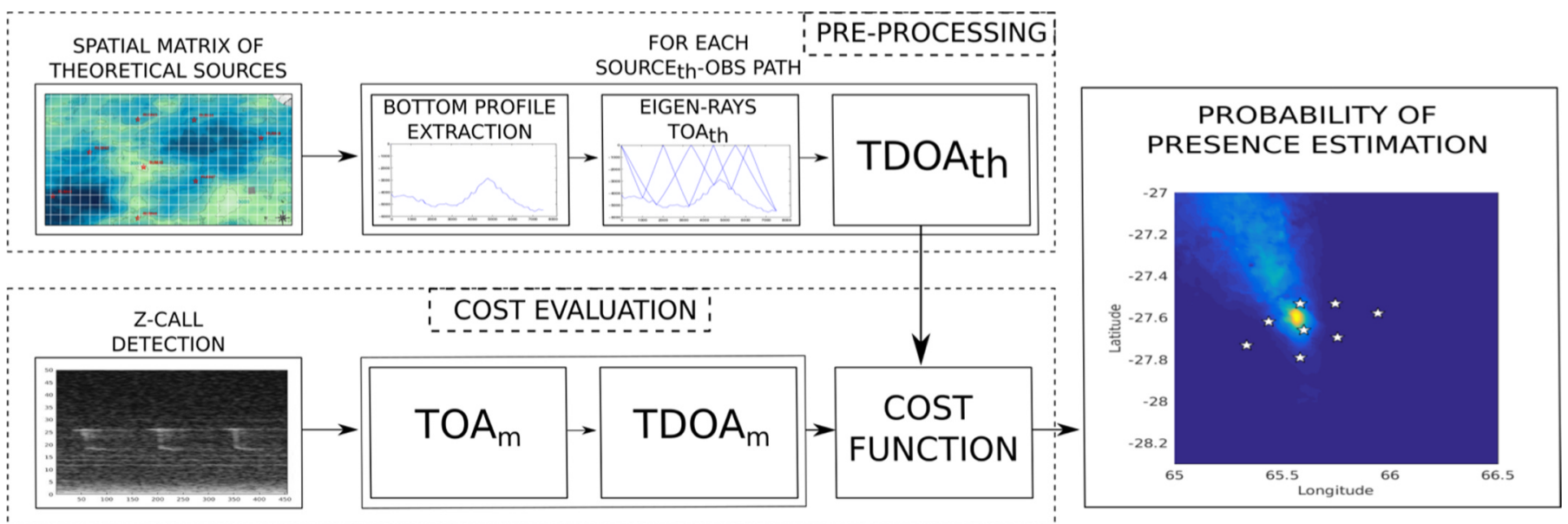

Fig. 5. Whale localization method considering environmental characteristics. A pre-processing step calculated $\mathrm{TDOA}_{\mathrm{th}}$. Then a cost function estimated the similarity between $\mathrm{TDOA}_{\mathrm{th}}$ and $\mathrm{TDOA}_{\mathrm{m}}$ to provide the probability of presence map Dréo et al. (2017).

frequency domain) corresponding to whale calls were composed by several rays, and could spread over $90 \mathrm{~s}$. This important delay probably due to reflexions on a lateral relief, and the high number of echoes highlighted that it was quite impossible to identify the different rays of a pattern. Hence, we assumed that only the first arriving ray could be reasonably considered as traveling along the source-sensor path (direct or reflected ray), and relevant for a TDOA based method.

\section{Results}

\subsection{Baleen whale acoustic signatures}

The vocal signatures of ABW, FW and MPBW were recurrently found in the data set, as well as a recently described song, from an unknown but probably baleen whale species, named "P-call" (Leroy et al., 2017) or "Spot-call" (Rhianne, 2017). These songs were described and illustrated on a high SNR observation. They were then compared with a remote recording to show the effect of propagation and environment characteristics.

\subsubsection{Antarctic blue whale}

Fig. $6 a$ is the time-frequency representation of a succession of 5 ABW calls recorded at station RR43 in the SWIR-array. From the tracking Section 4.3.1, the whale was estimated to be $\simeq 2 \mathrm{~km}$ away from the recording OBS. Fig. $6 \mathrm{~b}$ is an observation of the same calls recorded at a further OBS (RR47), $\simeq 26 \mathrm{~km}$ away. Fig. $6 \mathrm{c}$ represents the PSD of each observation.

The ABW call is named Z-call because of its recognizable Z-shape in the time-frequency domain. It is constituted of 3 parts: the first, called the unit $\mathrm{A}$, is a slightly modulated tone lasting $12.1 \pm 0.2 \mathrm{~s}$, with a peak frequency of $26.2 \pm 0.005 \mathrm{~Hz}(B T=1.3)$. It is also the most energetic component of the call (Bouffaut et al., 2017). It is followed by a short frequency-modulated down-sweep, unit $\mathrm{B}$, that lasts $\simeq 2 \mathrm{~s}$ and links unit A to $C(B T=20.2)$. Unit $C$ is also a slightly modulated tone of $12.2 \pm 0.4 \mathrm{~s}$, with a peak frequency at $18.7 \pm 0.007 \mathrm{~Hz}(B T=2.4)$. Zcalls were repeated with ICIs of $66.4 \pm 0.4 \mathrm{~s}$, and ISI of $206.4 \pm 9.9 \mathrm{~s}$.

On both spectrograms (Fig. 6a-b) a background noise covers a larger band than the one of the Z-calls. Fig. $6 \mathrm{c}$ is used to analyze the effect of propagation on the PSD. Units A and B respectively lost $\simeq 17 \mathrm{~dB}$ and $\simeq 11 \mathrm{~dB}$ between the two OBSs. Because it is drawn in background noise, the lower part of the call below $22.8 \mathrm{~Hz}$, is almost not visible on Fig. 6b. However it is not well highlighted by the difference of energy between units A and C which went from $19 \mathrm{~dB}$ to $13 \mathrm{~dB}$, due to the FW calls (see Section 4.1.2).

\subsubsection{Fin whale}

Fig. $7 \mathrm{a}$ is the time-frequency representation of 2 whole series constituted respectively by 15 and 14 calls of $2-5$ pulsed units. The whale was estimated from the tracking (see Section 4.3.2) at about $5 \mathrm{~km}$ to the OBS RR43. Fig. $7 \mathrm{~b}$ is an observation of the same call series recorded at a
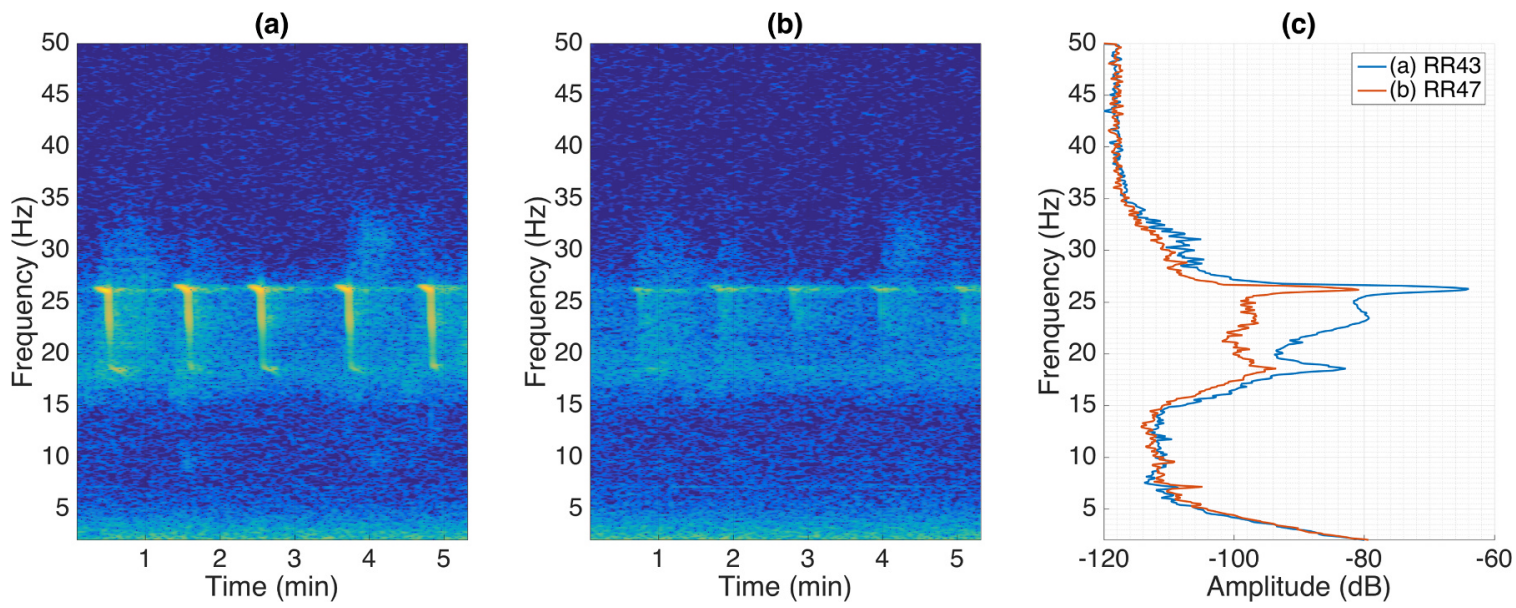

Fig. 6. Antarctic blue whale calls and propagation effects. Recording date: $31^{\text {st }}$ May 2013, at 1233 UTC. Spectrogram parameters: hanning window, FFT size $=1024$, overlap $=98 \%$, relative scale in $\mathrm{dB}$. (a) RR43, (b) RR47, (c) Comparative PSD. 
(a)

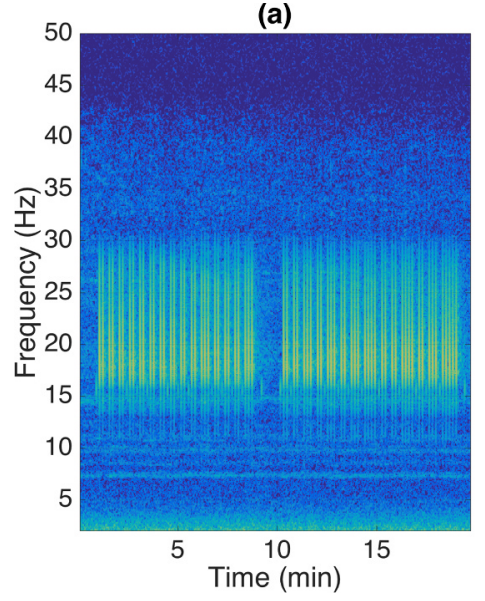

(b)

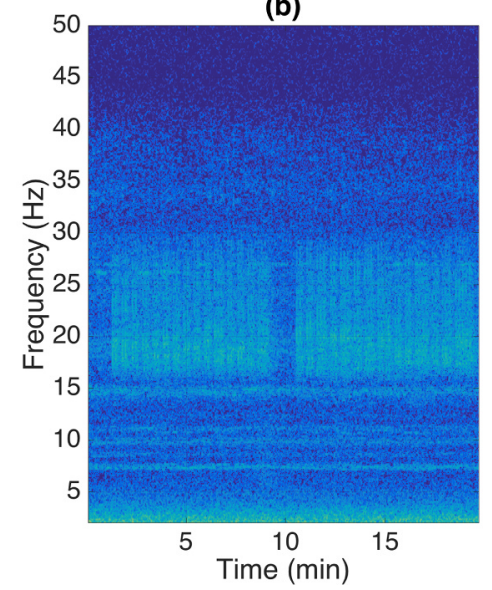

(c)

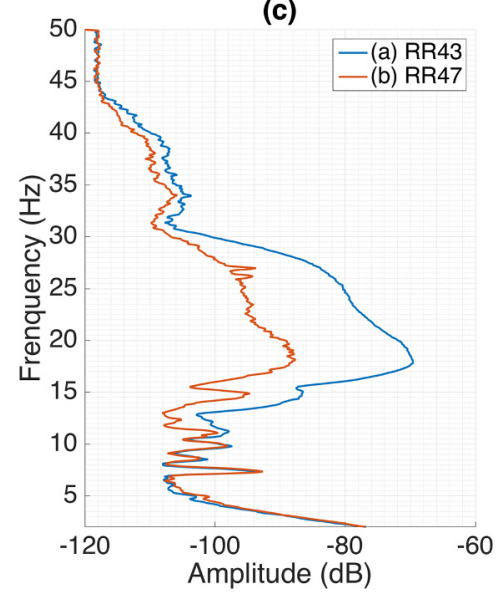

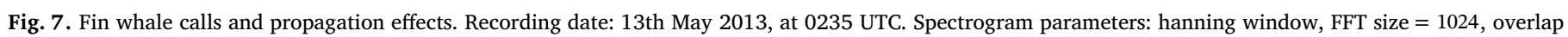
$=98 \%$, relative scale in $\mathrm{dB}$. (a) RR43, (b) RR47, (c) Comparative PSD.

further OBS (RR47), $\simeq 26 \mathrm{~km}$ away. Fig. 7c represents the PSD of each observation.

The FW call unit is a short duration broadband pulse $(<1 \mathrm{~s})$ named $20 \mathrm{~Hz}$-pulse (Watkins et al., 1987), ranging from 13 to $31.5 \mathrm{~Hz}$ $(B T=13.6)$. Most of the energy is concentrated around its maximum at $18.1 \pm 0.04 \mathrm{~Hz}$, between 16.9 and $20.2 \mathrm{~Hz}$ ( $-3 \mathrm{~dB}$ peak width). In our data set, this pulsed unit is repeated $2-5$ times to form a call. They are closely spaced, with an Inter Pulse Interval (IPI) of $9.9 \pm 0.04 \mathrm{~s}$. The ICI has a duration of $20.4 \pm 0.09 \mathrm{~s}$, and is repeated in series with an ISI of $107.6 \pm 4.9$ s. Small pulses of shorter frequency ranges $(\simeq 13-18 \mathrm{~Hz})$ sometimes occurred as an additional unit within the call. Due to the limited sample rate of the recordings, it is not known if these $20 \mathrm{~Hz}$ pulses occurred along with higher frequency components, as observed for instance near the Antarctic Peninsula (Širović et al., 2004).

The remote observation of the same series using Fig. 7a highlights several consequences of the propagation, that can be quantified using the comparative PSD on Fig. 7c. Pulses energy is $18 \mathrm{~dB}$ damped with the distance. The difference of energy within the call between $18.1 \mathrm{~Hz}$ and $25 \mathrm{~Hz}$ decreases from $11 \mathrm{~dB}$ to $5 \mathrm{~dB}$. The call bandwidth is narrower from [10.6 - 31.5] $\mathrm{Hz}$ to [15.4 - 30] $\mathrm{Hz}$ and its maximum is slightly shifted from $18.2 \mathrm{~Hz}$ to $18.8 \mathrm{~Hz}$. The monotonal noise centered around $14 \mathrm{~Hz}$ is likely generated by a ship passing in the vicinity of the station. Peaks at $26.2 \mathrm{~Hz}$ and $26.9 \mathrm{~Hz}$ are respectively due to ABW and P-calls (Section 4.1.1 and 4.1.4). Peaks at $\simeq 13.7 \mathrm{~Hz}$ and $\simeq 34 \mathrm{~Hz}$ are due to distant MPBW songs, that are described in section 4.1.3.

\subsubsection{Madagascan pygmy blue whale}

Fig. $8 \mathrm{a}$ is the time-frequency representation of 7 MPBW calls recorded at station RR47. The whale was estimated from the tracking to be at $\simeq 3 \mathrm{~km}$ to the OBS (see section 4.3.3). Fig. $8 \mathrm{~b}$ is an observation of the same call series from a further OBS (RR48), $\simeq 24 \mathrm{~km}$ away. Fig. $8 \mathrm{c}$ represents the PSD of each observation.

The MPBW call consists of two long units: the first one lasts $27.3 \pm 0.6 \mathrm{~s}$ with a fundamental frequency of $\simeq 13.5 \mathrm{~Hz}(B T=1.7)$. It presents harmonics with $7 \mathrm{~Hz}$ intervals, up to $34.0 \pm 0.02 \mathrm{~Hz}(B T=1.3)$. $10-15 \mathrm{~s}$ later follows the second unit, lasting $24.4 \pm 0.6 \mathrm{~s}$. Most of the energy is concentrated on a "triple down sweep" from $\simeq 24.4$ to $21.6 \mathrm{~Hz}$ with a maximum at $23.25 \pm 0.1 \mathrm{~Hz}(B T=18.2)$. Both calls start with a broadband signal constituted of multiple $\simeq 1.4 \mathrm{~Hz}$-spaced low energy harmonics. Calls were repeated with ICIs of $103.1 \pm 0.4 \mathrm{~s}$ and series are separated by ISIs of $302.4 \pm 49.4 \mathrm{~s}$. The observation on the remote OBS (Fig. 8b) highlights that the broadband part of units are attenuated with distance. The three harmonics of the first unit suffer from losses of $10 \mathrm{~dB}$ at $13.5 \mathrm{~Hz}, 8 \mathrm{~dB}$ at $20.5 \mathrm{~Hz}$ and $9 \mathrm{~dB}$ at $34 \mathrm{~Hz}$. The second unit "triple down sweep" looses $11 \mathrm{~dB}$. FW pulsed calls were more present on the remote observation in the $[16.3-19.5] \mathrm{Hz}$ band. The small peak at $26.7 \mathrm{~Hz}$.

\subsubsection{Unknown source (P-call)}

Fig. 9a is the time-frequency representation of 12 "P-calls" or "Spotcalls" (Leroy et al., 2017) recorded at station RR40. This OBS is outside of the SWIR array, hence the whale location could not be estimated.
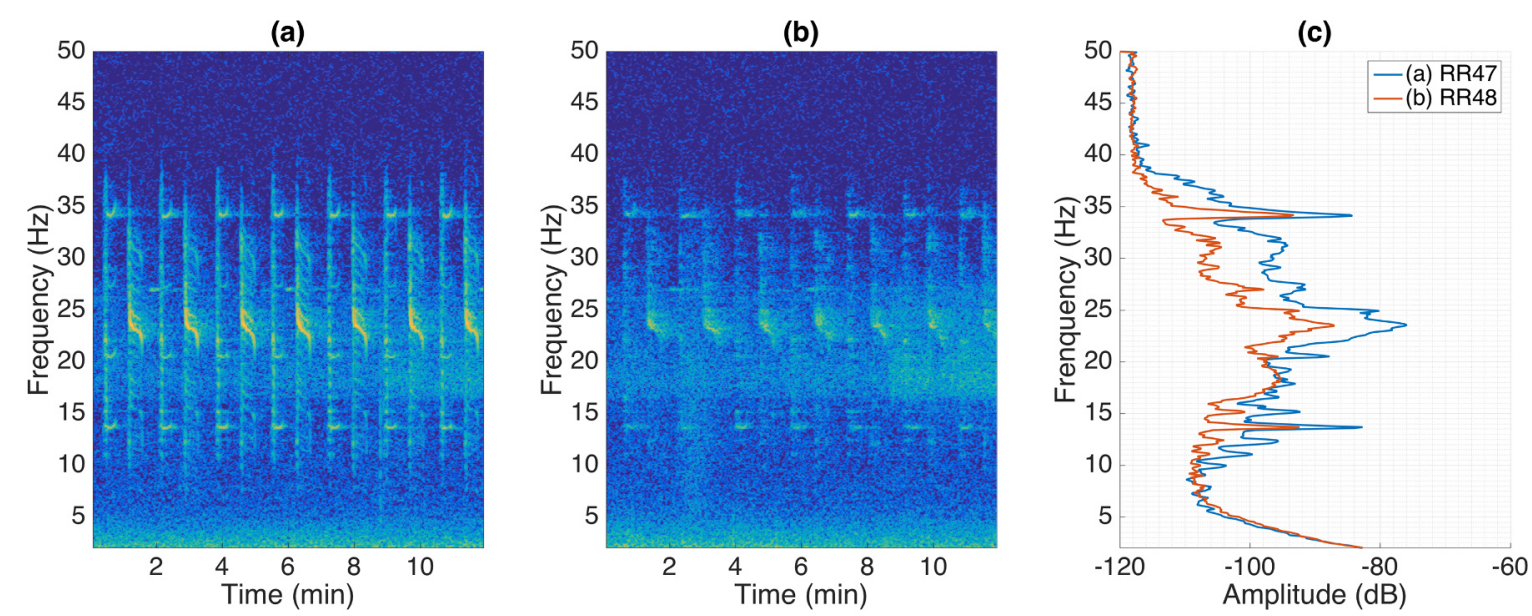

Fig. 8. Madagascan Pygmy Blue Whale calls and propagation effects. Recording date: $28^{\text {th }}$ May 2013, at 1846 UTC. Spectrogram parameters: hanning window, FFT size $=1024$, overlap $=98 \%$, relative scale in $\mathrm{dB}$. (a) RR47, (b) RR48, (c) Comparative PSD. 
(a)

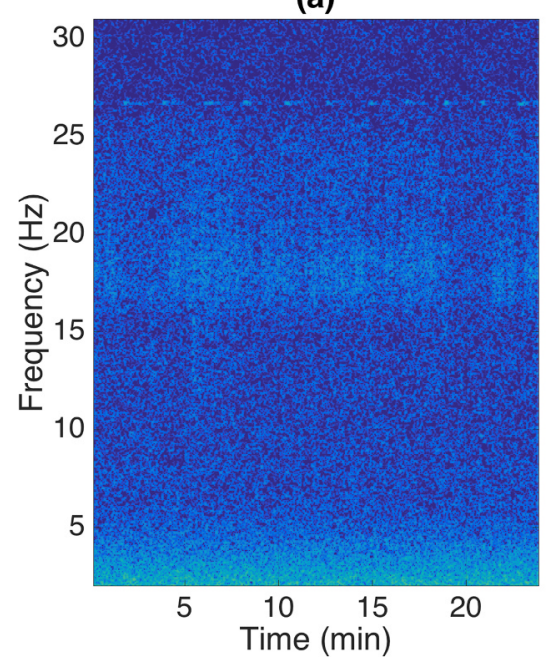

(b)

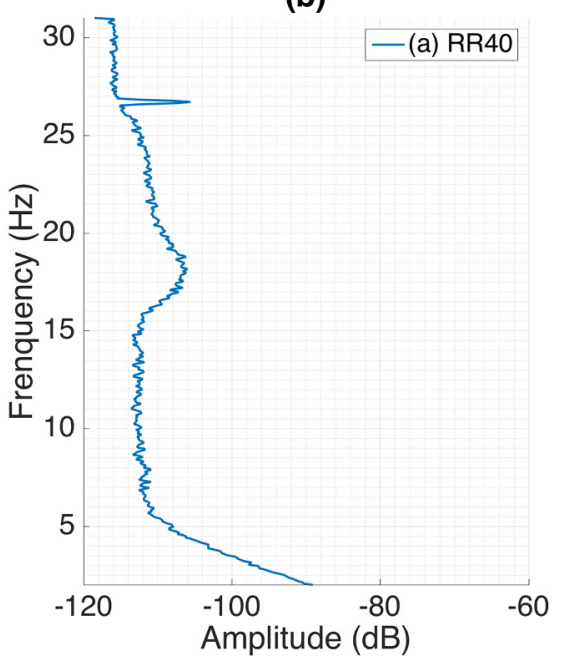

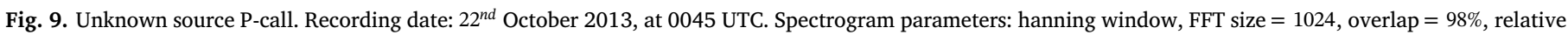
scale in dB. (a) RR40, (b) PSD.

Fig. 9b represents the PSD.

The "P-call" (Leroy et al., 2017) is a single tonal unit of $14.5 \pm 0.16 \mathrm{~s}$ of duration, with a peak frequency of $26.9 \pm 0.004 \mathrm{~Hz}(B T=1.6)$. It is repeated with an ICI of $132.1 \pm 0.94 \mathrm{~s}$. The analysis of the PSD stresses that "P-calls" frequency was just over the frequency band occupied by remote FW.

\subsection{Calls geographic and seasonal patterns}

The recorded data set provided a large variety of signals produced by baleen whales and identified by their specific acoustic signatures. The seasonal acoustic presence of these 4 different species and subspecies have been analyzed over the course of 13 months at 6 different OBSs (black stars in Fig. 1). All four baleen whale call types showed geographic and seasonal variation in their occurrences.

ABW calls were recorded at all six OBSs sites mainly from February to November, sometimes continuously, sometimes with one or two months of gaps (Fig. 10). No ABW calls were detected in December and January. At the eastern OBSs (RR50, RR52), calls were detected from February to November. At the western OBSs (RR28, RR29), the seasonal acoustic presence of the species was shorter and occurred mainly from mid-April to mid-August, and mid-September to mid-October.

FW calls were recorded continuously at all six OBSs sites mainly from May to November (Fig. 10). No FW calls were detected from December to March (summer months). Over the course of the year, FW calls were first and last detected at the southern OBS site (RR36). At the eastern and northern OBSs (RR28, RR29, RR52), the seasonal acoustic presence of the species was shorter and occurred mainly from June to November.

Compared to the above call types, MPBW calls were recorded only during a much limited period of the year, from March to June (Fig. 10). Over the course of the year, the species was first detected at the RR40 site and then few weeks later at the western OBSs sites (RR36, RR29, RR28) before disappearing from the network. Only rare detection have been made at the easternmost stations RR50 and RR52.

Finally, records of P-calls were limited to only three OBSs (RR36, RR40, RR50) and with a relatively strong seasonal pattern (Fig. 10). The distribution of the P-call presence by season was quite different among the OBSs: P-calls were recorded for the first time in March at the southern OBS site (RR36), and then from mid-April to October. Their presence is slightly delayed when going further east: 10 days later at RR40 and 1 month later at RR50 (relative to RR36). No P-calls were detected at the northern and western OBSs of the array (RR28, RR29 and RR52).

\subsection{Tracking whales using the local SWIR array}

The existence of a small and dense array of OBSs on the SWIR (see inset Fig. 1 and 3) allowed to detect and locate the baleen whales calls and therefore to determine their tracks. To demonstrate the feasibility of such approach and as a preliminary analysis of this 8 month-long data set, we performed track analyses on a single recording day for each species.

\subsubsection{Antarctic blue whale}

On May 31, 2013, ABW calls were detected continuously over 22 consecutive hours from 0100 to 2300 UTC. It was possible to track one individual from 0830 to 1330 UTC on 5 active OBSs from the SWIR array (Fig. 11). During this period, ICIs were very regular, suggesting that a single ABW was producing these calls (Fig. 6). This $5 \mathrm{~h}$ tracking revealed that the ABW moved in the middle of the SWIR array from southeast to northwest. The whale traveled $50 \mathrm{~km}$ with a mean speed of $10 \mathrm{~km} / \mathrm{h}$. Assuming the ABW kept the same mean speed from 0100 to 2300 UTC, we obtained a detection radius by the OBS of $\simeq 100 \mathrm{~km}$.

\subsubsection{Fin whale}

From May 13 to May 17, 2013, a FW traveled into the SWIR array during more than $90 \mathrm{~h}$ (Fig. 12). The tracking covers the first $18 \mathrm{~h}$. The FW described an erratic trajectory with mean speed varying between 2 and $3 \mathrm{~km} / \mathrm{h}$. Only one individual was detected.

\subsubsection{Madagascan pygmy blue whale}

During the 8-months recording of the experiment on the SWIR, very few MPBW calls were detected on this part of the RHUM RUM network. However, on May 28, 2013, MPBW calls were detected during 9 consecutive hours close to the OBS located at the northeast of the SWIR array. ICIs were regular, suggesting that a single MPBW sang at a time. However, 3 different tracks were obtained (Fig. 13). The first track started at 1628 until 2207 UTC in a constant direction (North). The whale traveled $30 \mathrm{~km}$ during less than $6 \mathrm{~h}$, from RR47 to RR44, with a mean speed of $\simeq 5 \mathrm{~km} / \mathrm{h}$. When this first whale stopped singing, another whale was immediately detected at $15 \mathrm{~km}$ in the South, and during $3 \mathrm{~h}$. The second calling whale mean speed was $4 \mathrm{~km} / \mathrm{h}$. Finally a third whale started singing in the North of the array at $18 \mathrm{~km}$ from the end of the first track, and $15 \mathrm{~km}$ from the end of the second track. It is impossible to conclude if it was a third individual, or the first one that 
Antarctic blue whale calls

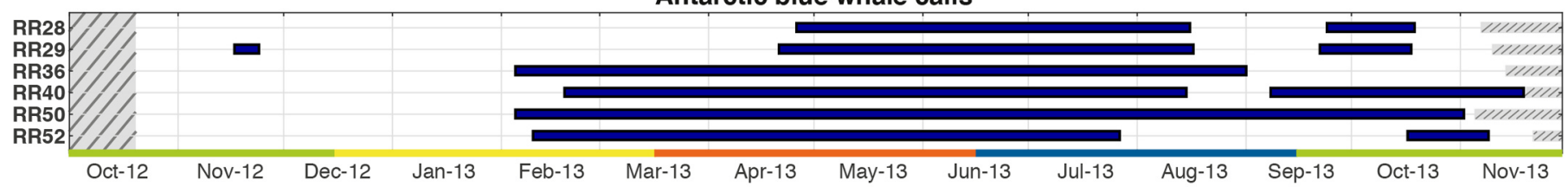

Madagascar pygmy blue whale calls
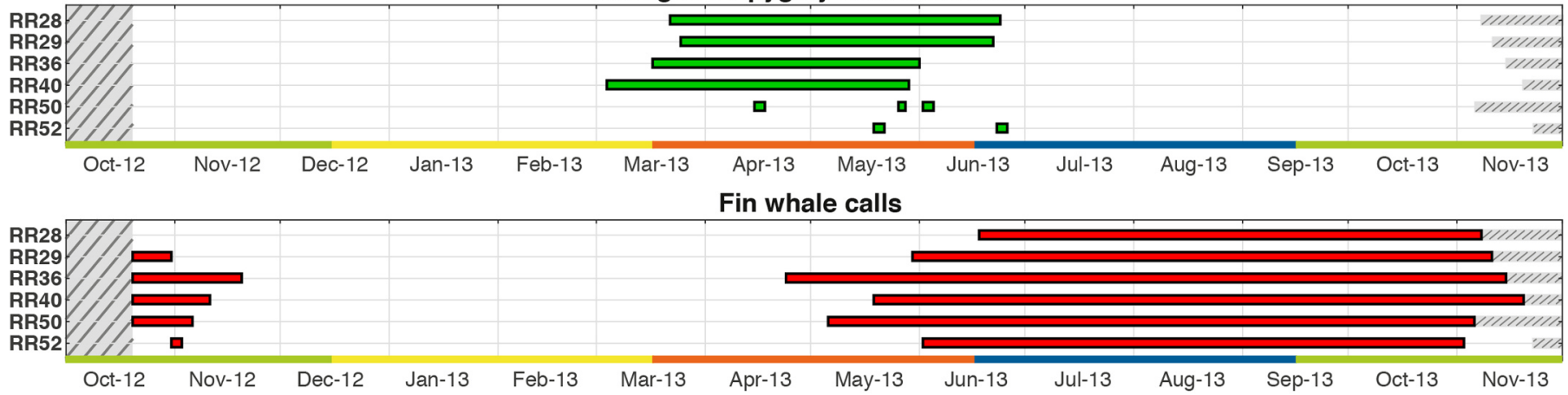

P-calls

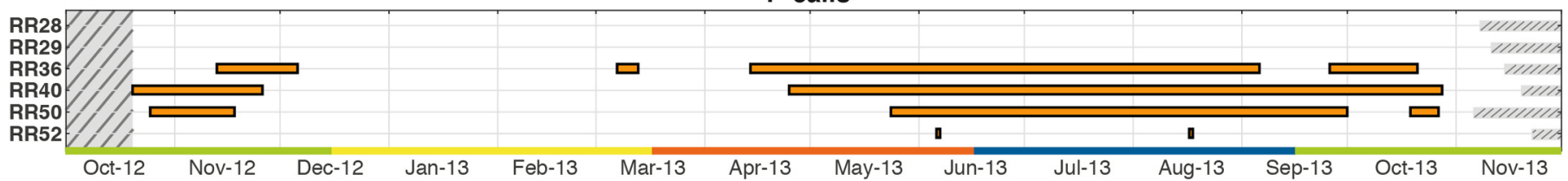

Fig. 10. Seasonal occurrence of the predominant frequency of ABW, MPBW, FW in their acoustic signatures and P-calls on each studied site from the RHUM-RUM network. Colored bar indicates call's presence. Grey period denotes the absence of data. Horizontal color evolution outlines the season (from left to right: spring 2012, summer 2012, fall 2013, winter 2013, spring 2013).

traveled quietly to the West.

\section{Discussion}

The seasonal occurrence, distribution and tracking of different species of baleen whales in western IO were assessed through the sounds of their calls recorded in a temporary network of autonomous OBSs. This study illustrated that the deployment of seafloor seismic arrays can be a valuable source of data, not only for seismological purposes, deep Earth imaging and monitoring but also for biological and environmental purposes. The passive recording on the ocean floor is obviously of great interest for analyzing animal behavior without

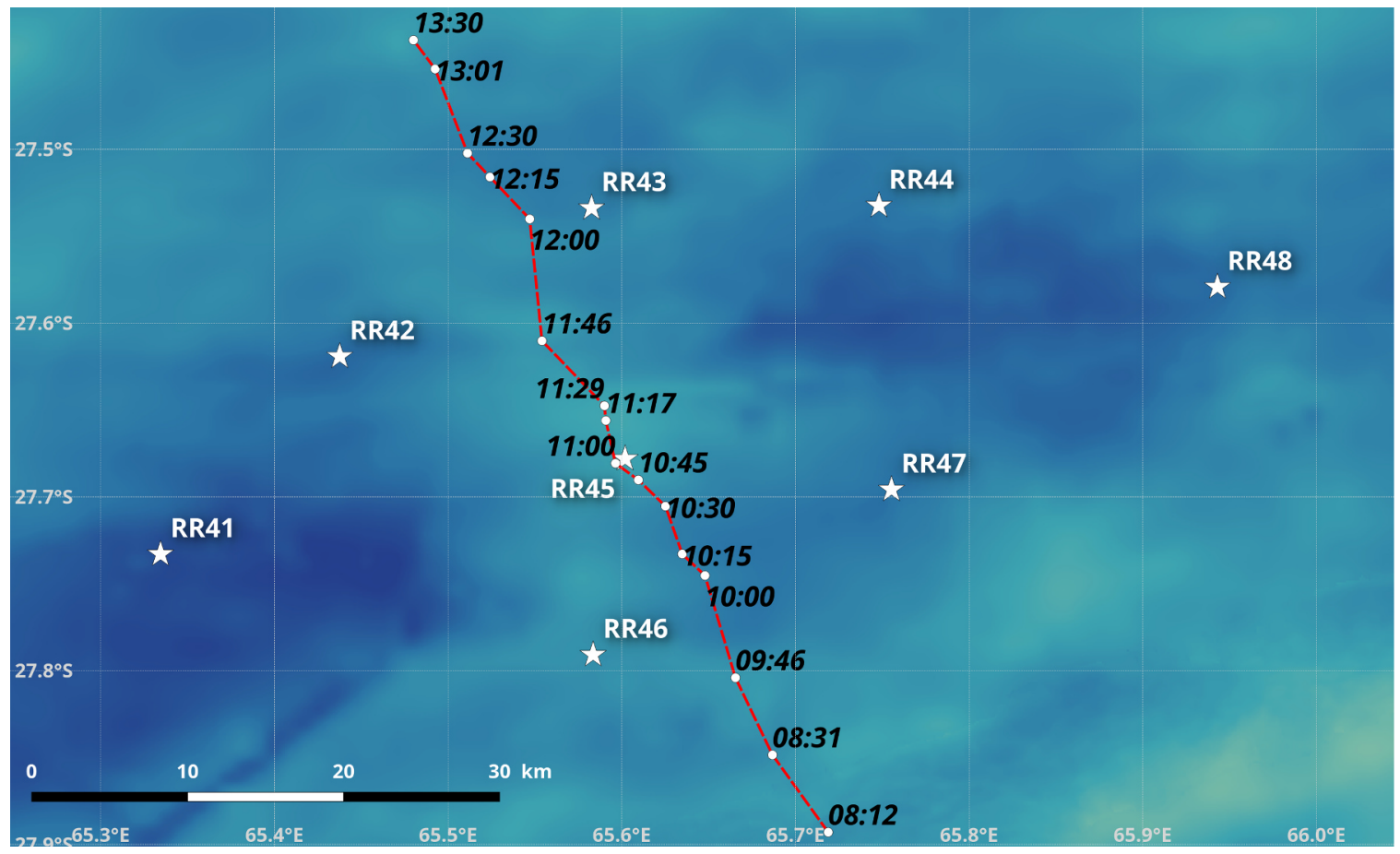

Fig. 11. ABW Tracking - May 31, 2103. 


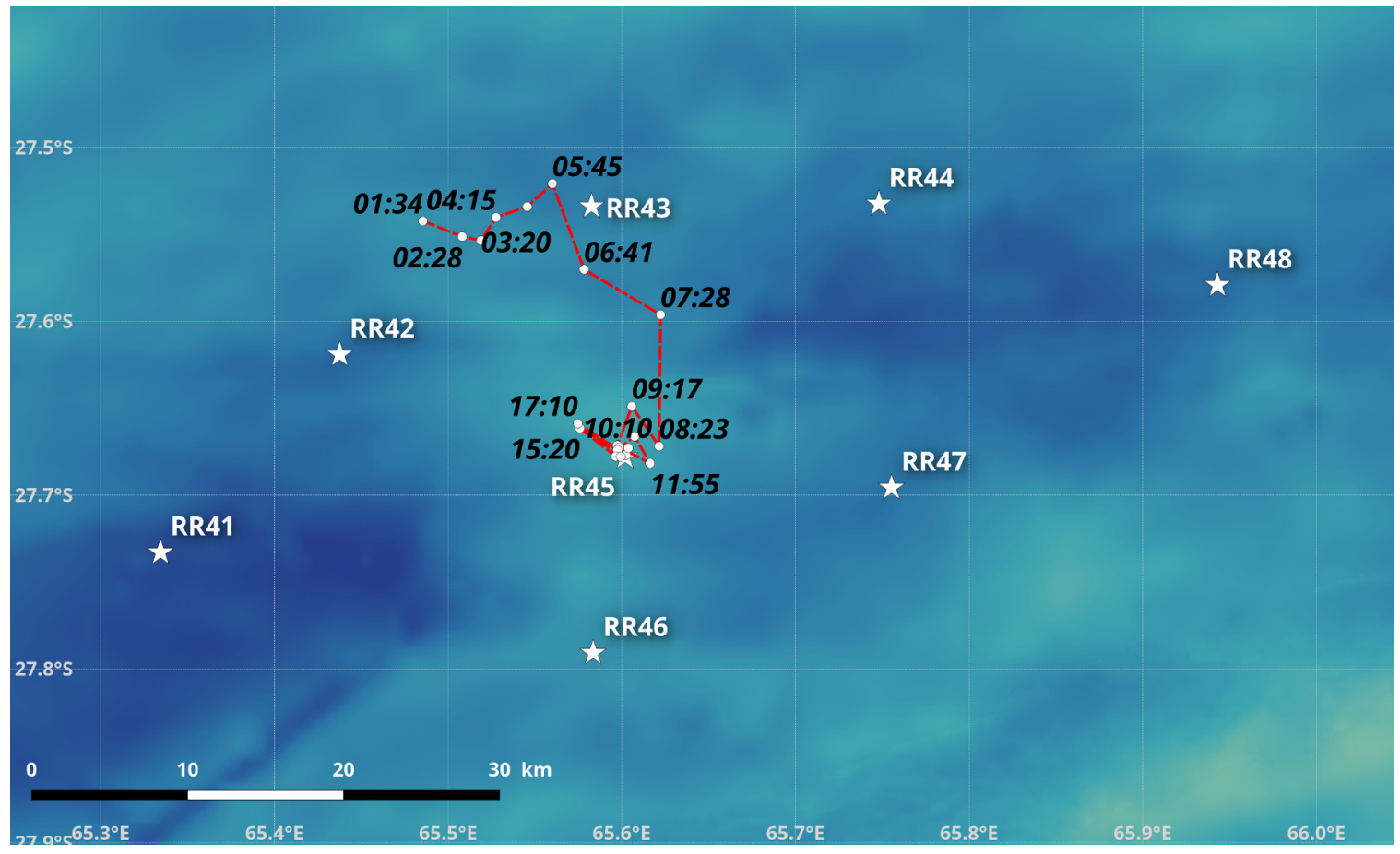

Fig. 12. FW Tracking $13^{\text {th }}$ May 2013.

human disturbance.

Although OBSs were recording on the seafloor and not in the SOFAR channel, they provided continuous high quality call series over a large detection radius: the ABW tracking example (Section 4.3.1) showed a detection radius of $\simeq 100 \mathrm{~km}$ and observations over $23 \mathrm{~h}$. The study of remote calls demonstrated however, that there is an impact of the source distance on the aspect of the received signals. It leads to multiple echoes, spreading calls energy in time towards reverberation. The multiple reflections of regularly repeated calls insonify this frequency band and minimize call SNR (Leroy et al., 2016).
The acoustic data set recorded by the RHUM-RUM network revealed the presence of four different vocal signatures of baleen whales in the [0-50] Hz bandwidth. These species were severely affected by commercial whaling during the 20th century, sometimes brought to the edge of extinction. For instance, ABW, PBW and FW figure on the Red List of the IUCN (International Union for Conservation of Nature (Reilly et al., 2008)), under different status: "Critically Endangered" for ABW, "Endangered" for FW and finally "Data deficient" for PBW. In this particular case, uncertainties still exist about their abundance, and nowadays PAM is one of the most powerful tool to fill this lack of

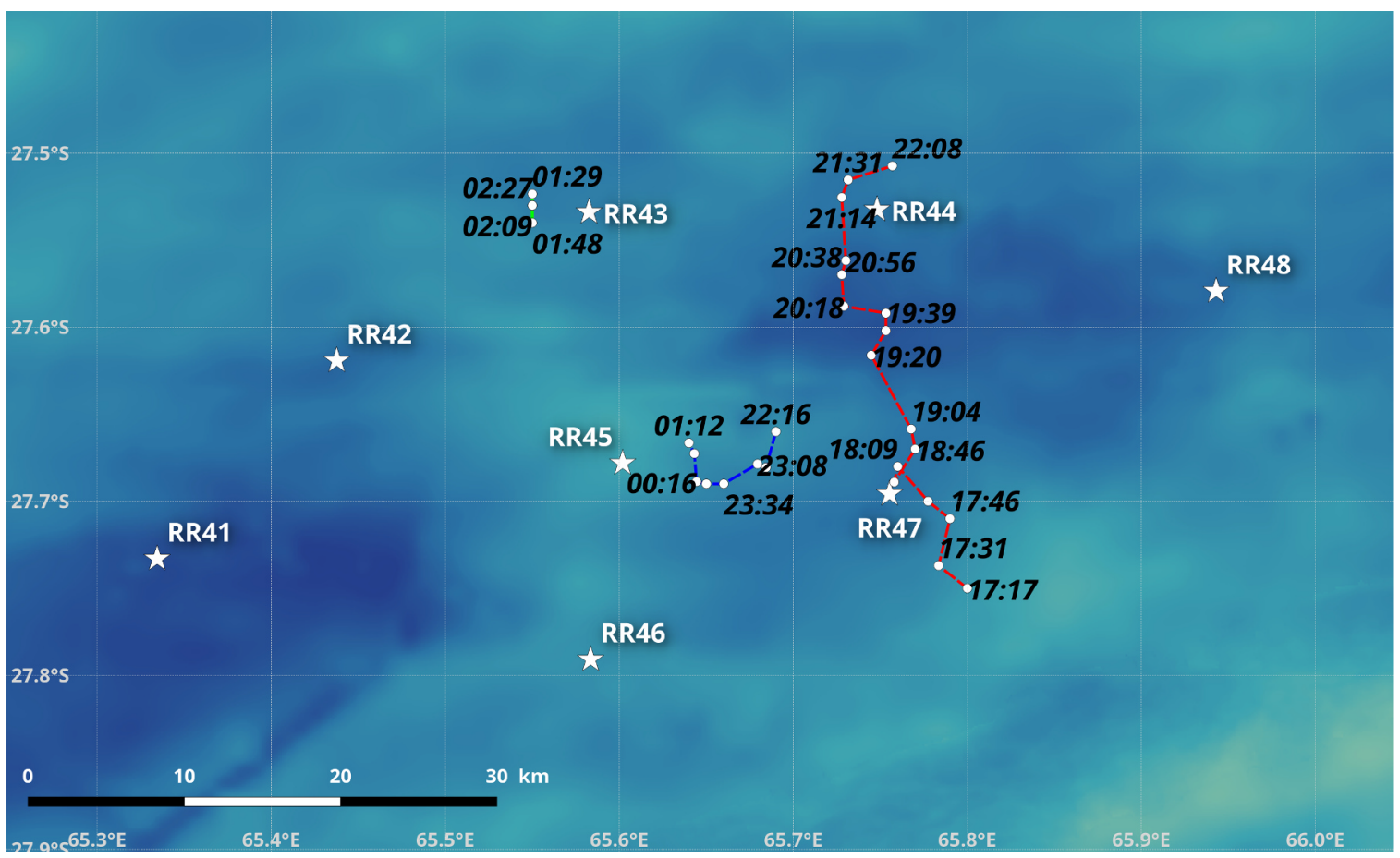

Fig. 13. MPBW Tracking $28-29^{\text {th }}$ May 2013. 
knowledge. In the past decade, acoustic studies also revealed the importance of the IO for these species and subspecies, as a potential migrating and wintering area (Stafford et al., 2004, 2011; Samaran et al., 2010b, 2013). More recently, 6 years-long acoustic observations (Leroy et al., 2016; Leroy, 2017) were conducted on a large area of the southern IO and confirmed the importance of the region. Finally, the analysis of the RHUM-RUM data provided the opportunity to refine the knowledge on species dwelling in this part of the western IO.

Blue whales produce regionally-distinct songs (McDonald et al., 2006). In the Southern Hemisphere, ABW call is the most widely distributed blue whale vocal signature, and is found from the Southern Ocean, near Antarctica (Širović et al., 2004, 2009; Širović, 2006; Thomisch et al., 2016) up to mid and lower latitudes of the other oceans, and particularly of the IO (Samaran et al., 2010b, 2013; Leroy et al., 2016; Balcazar et al., 2017). This typical Z-shape signature was found from February to November in our OBS network and no ABW calls were found during December and January. This seasonality is in agreement with the results of the previous studies in the area (Stafford et al., 2004; Samaran et al., 2010b, 2013; Leroy et al., 2016). ABW are found largely south in the austral summer (December to February) when the main part of the population is feeding on the Antarctic feeding grounds, and then likely spread out over a broader range in the IO during the austral winter (June to August) when they stay during a longer period of time. The wintering area of this blue whale subspecies encompasses a large part of the studied area.

Like blue whales, FW produce relatively simple signals. The " $20 \mathrm{~Hz}$ pulse" is the most commonly observed call unit. However, it appears that FW songs, and more particularly their IPIs, vary geographically (Castellote et al., 2012; Thompson et al., 1990; Delarue et al., 2009; Širović et al., 2017), and that they also display changes over long-term periods (Oleson et al., 2014; Weirathmueller et al., 2017). Although being one of the most studied large whale sounds, as it is recorded in all the oceans (Širović et al., 2009; Stafford et al., 2009; Nieukirk et al., 2012), so far, no study on FW songs exists in the IO. In the Antarctic, FW calls appear to be constituted of singlet pulses with regular IPIs, cooccurring with a higher note, around 90 or $100 \mathrm{~Hz}$ (Širović et al., 2009, 2004). In the IO, preliminary analysis show a similar call type, with an upper note around $100 \mathrm{~Hz}$ (Leroy, 2017). However, in our data set, this upper note could not be observed due to the too low sample frequency. In the measured FW calls used to estimate the swim track, the pulsed units were patterned in groups of $2-5$ pulses with short IPIs $(\simeq 10 \mathrm{~s})$ to form a call, and these groups were separated with longer ICI pauses $(\simeq$ $20 \mathrm{~s}$ ). These patterns differ from the calls observed in the Southern Ocean (Širović, 2006; Širović et al., 2009), suggesting a different population. Further analyses are required to explore if other FW call types exist in our recordings. FW are found in all oceans of the world and may migrate from subtropical waters during the winter to the colder areas of the Arctic and Antarctic for feeding during the summer (Perry et al., 1999). Previous acoustic studies within the southern IO have detected FW songs all year long with highest levels during austral winter months (between May and July) (Tsang-Hin-Sun et al., 2015; Leroy, 2017). Here, FW appeared to be present in our study area from the end of April to November. FW seemed to start singing or to be present in the vicinity of the study area at the end of April and spread out over a broader range in the western IO for austral winter. Moreover, no FW songs were recorded from December to March (austral summer), when they are supposed to be on the Antarctic feeding grounds (Širović et al., 2004; Širović, 2006). Our study demonstrates that the western IO may be part of the migration route and/or breeding area or at least winter location of FW populations.

The IO has the largest variety of blue whale vocal signatures including different "acoustic populations" of PBW based on the timefrequency characteristics of their sounds, which are readily distinguishable from one another. These "acoustic populations" differ according to the location in the IO in which they are recorded (McDonald et al., 2006; Samaran et al., 2010b, 2013; Leroy et al., 2016; Balcazar et al., 2017). The only PBW call type recorded in our OBS array is the Madagascan call type (song type 9A (McDonald et al., 2006)). This call type was recorded in the presence of PBW on the Madagascar Plateau and was attributed to the PBW of the sub-Antarctic region (Ljungblad et al., 1998). Recent PAM studies in the IO revealed detection of this call type across the IO from Diego Garcia in the north (Stafford et al., 2011), Crozet Islands and Kerguelen plateau in the south (Samaran et al., 2010b, 2013; Tsang-Hin-Sun et al., 2015; Leroy, 2017), Madagascar plateau in the west (Ljungblad et al., 1998) and south west of Amsterdam island in the east (Samaran et al., 2013; Tsang-Hin-Sun et al., 2015; Leroy, 2017). Here, this MPBW calls were detected mainly in the western part of our network of OBSs. The predominant frequency of this call was detected during a few days at the eastern OBS that could delimit the distribution of the population at around $65^{\circ} \mathrm{E}$ at least in these mid latitudes. The MPBW calls were detected in our OBS array during a couple of months from March to June (austral autumn months). This seasonality is in agreement with the results of previous studies in the area (Samaran et al., 2013; Tsang-Hin-Sun et al., 2015; Leroy, 2017). The absence of calls from December to March (austral summer months) may explain the distribution of the population during feeding period, since the population was previously detected at higher sub-Antarctic latitudes in summer (Samaran et al., 2010b, 2013; TsangHin-Sun et al., 2015; Leroy, 2017). Also, our study demonstrates that the western IO is not a winter or spring locations for this population of PBW. So far, these locations are still not known, since, in the IO, this call type was detected only from January to June (austral summer and autumn months) (Samaran et al., 2010b, 2013; Stafford et al., 2011; Tsang-Hin-Sun et al., 2015; Leroy, 2017).

The OBSs network recorded a type of call with similar features of a recently described song called "P-calls" or "Spot-call". This call has not been attributed to any baleen whale yet. However, it is assumed to be produced neither by ABW nor PBW (Leroy et al., 2017; Rhianne, 2017). These recent PAM studies revealed detection of this call type in deepocean waters across the IO from $26^{\circ} \mathrm{S}$ to $42^{\circ} \mathrm{S}$ and from $058^{\circ} \mathrm{E}$ to $083^{\circ} \mathrm{E}$ (Leroy et al., 2017) and in the Southern and Indian oceans off Australia within $32^{\circ} \mathrm{S}$ to $38^{\circ} \mathrm{S}$ and $110^{\circ} \mathrm{E}$ to $141^{\circ} \mathrm{E}$ (Rhianne, 2017). Off Australia, this call type was detected exclusively during austral winter and spring months while, in the southern IO, this call type was detected from late summer to late fall at the east part of the southern IO and during winter and spring in the west part of the IO. The acoustic detection of this unknown call in our network of OBSs confirmed the presence of the species in the western IO with a limit of distribution at $25^{\circ} \mathrm{S}$ and $056^{\circ} \mathrm{E}$. This call type started to be detected in the western OBS in March and almost two months later at the eastern OBS suggesting a slow west-east movement of the species from March to June (austral autumn months). This call type was detected in the study area until December (end of austral spring). Our new results highlight the complexity of the seasonal pattern of distribution of this unknown species but confirm that the western IO is definitely not a summer location. Moreover, these analyses allow defining the limit north of their distribution at least during austral winter and spring months.

The tracking of singing blue whales and FW was realized on trajectories passing through the SWIR array. The tracking method revealed punctual locations on their track, from handpicked calls. Dive depths were not studied. Trajectory of one ABW was studied using $5 \mathrm{~h}$ of records from May 31, 2013. The FW trajectory was estimated from $18 \mathrm{~h}$ data on May 13, 2013. Three different tracks of MPBW were detected in the vicinity of the array between May 28 and 29, 2013 over 9 consecutive hours. On the MPBW dataset, there were almost no overlapping of calls. However, the tracking revealed 3 different trajectories suggesting that 2 or 3 MPBW were closely spaced and acoustically active. Their swim speed was about $5 \mathrm{~km} / \mathrm{h}$, consistent with reported speeds for cruising or migrating blue whales (Mate et al., 1999; Gavrilov et al., 2012). The ABW and FW were traveling alone or at least without other singing whale. It is coherent with previous genetic and acoustic studies that showed that repetitive sequences of ABW and FW 
calls are characteristic of alone migrating males, rather than foraging whales or whales in groups (Croll et al., 2002; Oleson et al., 2007). The average swim speed of the ABW was $10 \mathrm{~km} / \mathrm{h}$ over the course of monitoring. The traveled distance and swim speeds were quite high, but confirmed that this individual was not in foraging activity. Maximum speeds of FW have been reported up to $36 \mathrm{~km} / \mathrm{h}$ (Gambell, 1985) but average speeds observed over long distance tracks are only $27 \mathrm{~km} / \mathrm{h}$ (Notarbartolo-Di-Sciara et al., 2003). Here, the FW lingered in the SWIR area with a mean speed of $2-3 \mathrm{~km} / \mathrm{h}$. This study highlights the interests of using such an OBSs array to track migrating whales. Our method's resolution is limited by the spatial matrix to the kilometer. However in further work, this resolution will be improved to provide better insights on whales local displacements. To analyze the whole dataset and to increase the number of location samples on each swim track, an automatic detection algorithm is needed (Bouffaut et al., 2017; Socheleau et al., 2015).

\section{Conclusion}

Given the relative paucity of blue and fin whale sighting data from the deep-waters of the western IO, these new data acquired on the ocean floor highlight the effectiveness of using passive acoustic monitoring to provide relevant information to assess the seasonal occurrence and distribution of populations. Our data demonstrates that OBS are perfectly suitable for detecting and tracking whales in the open oceans, providing new opportunities in bridging seismology and bioacoustics experiments. We showed that four different species or subspecies of baleen whales occurred sympatrically in the western IO, at least during fall months emphasizing the importance of this region for these populations. The area seems to be clearly a winter and spring locations for Antarctic blue and fin whales but not for the Madagascan pygmy blue whales. The results improve and complete our understanding of the migration and distribution patterns of blue whale subspecies and fin whales. This new information could be helpful to assess the conservation status and management of these species.

\section{Acknowledgements}

The RHUM-RUM project (http://www.rhum-rum.net (RHUMRUM)) was funded by ANR (Agence Nationale de la Recherche) in France (project ANR-11-BS56-0013) and by DFG (Deutsche Forschungsgemeinschaft) in Germany (grants SI1538/2-1 and SI1538/ 4-1). Additional support was provided by CNRS (Centre National de la Recherche Scientifique, France), TAAF (Terres Australes et Antarctiques Françaises, France), IPEV (Institut Polaire Franais Paul Emile Victor, France) and AWI (Alfred Wegener Institute, Bremerhaven, Germany). We thank DEPAS (Deutsche Geräte-Pool für Amphibische Seismologie, Germany), GEOMAR (GEOMAR Helmholtz-Zentrum für Ozeanforschung Kiel, Germany) and INSU-IPGP (Institut National des Sciences de 1'Univers - Institut de Physique du Globe de Paris, France) for providing 57 ocean-bottom seismometers. The RHUM-RUM data set (http://dx.doi.org/10.15778/RESIF.YV2011 (Rhum-rum dataset)) is hosted and served by the French RESIF data centre (http:// seismology.resif.fr (RESIF)) under the FDSN network code YV. Thanks to all cruise participants on R/V Marion Dufresne, cruise MD192 and on R/V Meteor, cruise M101.

\section{References}

Balcazar, N.E., Tripovich, J.S., Klinck, H., Nieukirk, S.L., Mellinger, D.K., Dziak, R.P. Rogers, T.L., 2015. Calls reveal population structure of blue whales across the southeast indian ocean and southwest pacific ocean. J. Mammal. 96 (6), 1184

Balcazar, N.E., Klinck, H., Nieukirk, S.L., Mellinger, D.K., Klinck, K., Dziak, R.P., Rogers, T.L., 2017. Using calls as an indicator for antarctic blue whale occurrence and distribution across the southwest pacific and southeast indian oceans. Mar. Mamm. Sci. 33 (1), 172-186.

Barruol, G., Sigloch, K., 2013. Investigating La Réunion hot spot from crust to core. Eos,
Trans. Am. Geophys. Union 94 (23), 205-207.

Barruol, G., Sigloch, K., group, R.-R., 2017. RHUM-RUM experiment, 2011-2015, code YV (Réunion Hotspot and Upper Mantle - Réunion's Unterer Mantel) funded by ANR, DFG, CNRS-INSU, IPEV, TAAF, instrumented by DEPAS, INSU-OBS, AWI and the Universities of Muenster, Bonn, La Réunion.

Bouffaut, L., Dréo, R., Labat, V., Boudraa, A.-O., Barruol, G., 2017. Antarctic blue whale calls detection based on an improved version of the stochastic matched filter, in EUSIPCO 2017, (Greece), August.

Bouffaut, L., Dréo, R., Labat, V., Boudraa, A.-O., Barruol, G., 2017. Remote blue whale call detection using a passive version of the stochastic matched filter, in UACE 2017, (Greece), Septembre.

Branch, T.A., Stafford, K.M., Palacios, D.M., Allison, C., Bannister, J.L., Burton, C.L.K. Cabrera, E., Carlson, C.A., Galletti Vernazzani, B., Gill, P.C., Hucke-Gaete, R., Jenner, K.C.S., Jenner, M.-N.M., Matsuoka, K., Mikhalev, Y.A., Miyashita, T., Morrice, M.G., Nishiwaki, S., Sturrock, V.J., Tormosov, D., Anderson, R.C., Baker, A.N., Best, P.B., Borsa, P., Brownell Jr, R.L., Childerhouse, S., Findlay, K.P., Gerrodette, T., Ilangakoon, A.D., Joergensen, M., Kahn, B., Ljungblad, D.K., Maughan, B., McCauley, R.D., Mickay, S., Norris, T.F., Whale, O., Group, D.R., Rankin, S., Samaran, F., Thiele, D., Van Waerebeek, K., Warneke, 2007. Past and present distribution, densities and movements of blue whales Balaenoptera musculus in the southern hemisphere and northern indian ocean. Mammal. Rev. 37 (2), 116-175.

Castellote, M., Clark, C.W., Lammers, M.O., 2012. Fin whale (Balaenoptera physalus) population identity in the western mediterranean sea. Mar. Mamm. Sci. 28 (2), 325-344.

Croll, A., Donald, Clark, W., Christopher, Acevedo, A., Tershy, B., Flores, S., Gedamke, J., Urban, J., 2002. Bioacoustics: only male fin whales sing loud songs. Nature 417.

Davy, C., Barruol, G., Fontaine, F.R., Sigloch, K., Stutzmann, E., 2014. Tracking major storms from microseismic and hydroacoustic observations on the seafloor. Geophys. Res. Lett. 41 (24), 8825-8831 (2014GL062319).

De Boer, M., Baldwin, R., Burton, C., Eyre, E., Jenner, K., Jenner, M.-N., Keith, S. McCabe, K., Parsons, E., Peddemors, V., Rosenbaum, H., Rudolph, P., Simmonds, M., 2003. Cetaceans in the Indian Ocean Sanctuary: a review. Whales Dolphins Conserv. Soc. 05.

Delarue, J., Todd, S.K., Van Parijs, S.M., Di Iorio, L., 2009. Geographic variation in northwest atlantic fin whale (Balaenoptera physalus) song: implications for stock structure assessment. J. Acoust. Soc. Am. 125 (3), 1774-1782.

Double, M.C., Andrews-Goff, V., Jenner, K.C.S., Jenner, M.-N., Laverick, S.M., Branch, T.A., Gales, N.J., 2014. Migratory movements of pygmy blue whales (Balaenoptera musculus brevicauda) between australia and indonesia as revealed by satellite telemetry. PLOS ONE 9, 1-11 (04).

Dréo, R., Bouffaut, L., Guillon, L., Labat, V., Boudraa, A.-O., Barruol, G., 2017. Antarctic blue whale localization with ocean bottom seismometer in southern indian ocean. In UACE 2017, (Greece), Septembre.

Dunn, R.A., Hernandez, O., 2009. Tracking blue whales in the eastern tropical pacific with an ocean-bottom seismometer and hydrophone array. J. Acoust. Soc. Am. 126 (3), 1084-1094.

Gambell, R., 1985. Finwhale Balaenoptera Physalus. Academic Press, pp. 3171-3192.

Gavrilov, A.N., McCauley, R.D., 2013. Acoustic detection and long-term monitoring of pygmy blue whales over the continental slope in southwest australia. J. Acoust. Soc. Am. 134 (3), 2505-2513.

Gavrilov, A., McCauley, R., Pattiaratchi, C., Bondarenko, O., 2012. The use of passive acoustics to observe the presence and movement of pygmy blue whales (Balaenoptera musculus brevicauda) in the Perth Canyon, WA, vol. 34 2, pp. 1802-1809. United States: International Institute of Acoustics and Vibration, part 3 ed., 12.

Gill, P., Morrice, M., Page, B., Pirzl, R., Levings, A., Coyne, M., 2011. Blue whale habitat selection and within-season distribution in a regional upwelling system off southern australia. Mar. Ecol. Prog. Ser. 421, 243-263 (01).

Hable, S., Sigloch, K., Barruol, G., Stähler, S.C. and Hadziioannou, C., 2018. Clock errors in land and ocean bottom seismograms: High-accuracy estimates from multiplecomponent noise cross-correlations. Geophys. J. Int., submitted.

Harris, D., Matias, L., Thomas, L., Harwood, J., Geissler, W.H., 2013. Applying distance sampling to fin whale calls recorded by single seismic instruments in the northeast atlantic. J. Acoust. Soc. Am. 134 (5), 3522-3535.

Hyrenbach, K.D., Forney, K.A., Dayton, P.K., 2000. Marine protected areas and ocean basin management. Aquat. Conserv.: Mar. Freshw. Ecosyst. 10 (6), 437-458.

Ivansson, S., 2017. Sound propagation modeling. In Applied Underwater Acoustics, pp. 185-272, Elsevier.

IWC, Chairman's report of the thirty-first annual meeting, Report of the International Whaling Commission, p. 30:25-41, 1980.

Kiszka, J., Vely, M., Breysse, O., 2010. Preliminary account of cetacean diversity and humpback whale (Megaptera novaeangliae) group characteristics around the union of the comoros (mozambique channel). Mammalia 74 (03).

Leatherwood, S., 1986. Whales, dolphins and porpoises of the Indian Ocean Sanctuary: A catalogue of available information. No. 87-197, Hubbs Marine Research Center Technical Report.

Leroy, e., 2017. Signaux acoustiques de baleines bleues dans l'océan indien austral: traitement, analyse et interprétation des signaux (Ph.D. thesis). Université Bretagne Occidentale.

Leroy, E.C., Samaran, F., Bonnel, J., Royer, J.-Y., 2016. Seasonal and diel vocalization patterns of antarctic blue whale (Balaenoptera musculus intermedia) in the southern indian ocean: a multi-year and multi-site study. PLOS ONE 11 (11), 1-20.

Leroy, E.C., Samaran, F., Bonnel, J., Royer, J.-Y., 2017. Identification of two potential whale calls in the southern indian ocean, and their geographic and seasonal occurrence. J. Acoust. Soc. Am. 142 (3), 1413-1427.

Ljungblad, D.K., Clark, C.W., Shimada, H., 1998. A comparison of sounds attributed to pygmy blue whales (Balaenoptera musculus brevicauda) recorded south of the 
madagascar plateau and those attributed to true'blue whales (Balaenoptera musculus) recorded off antarctic. Rep. Int. Whal. Comm (48:439-442).

Mate, B.R., Lagerquist, B., Calambokidis, J., 1999. Movements of north pacific blue whales during the feeding season off southern california and their southern fall migration. Mar. Mammal. Sci. 15, 1246-1257 (10).

McDonald, M.A., Mesnick, S.L., Hildebrand, J.A., 2006. Biogeographic characterization of blue whale song worldwide: using song to identify populations. J. Cetacea. Res. Manag. 8 (1), 55-65.

Mellinger, D.K., Stafford, K.M., Moore, S., Dziak, R.P., Matsumoto, H., 2007. Fixed passive acoustic observation methods for cetaceans. Oceanography 20 (4), 36.

Nieukirk, S.L., Mellinger, D.K., Moore, S.E., Klinck, K., Dziak, R.P., Goslin, J., 2012. Sounds from airguns and fin whales recorded in the mid-atlantic ocean, 1999-2009. J. Acoust. Soc. Am. 131 (2), 1102-1112.

Notarbartolo-Di-Sciara, G., Zanardelli, M., Jahoda, M., Panigada, S., Airoldi, S., 2003. The fin whale Balaenoptera physalus (1. 1758) in the mediterranean sea. Mamm. Rev. 33 (2), 105-150.

Ocean acoustics library web page. 〈http://oalib.hlsresearch.com/Rays/〉.

Oleson, E.M., Wiggins, S.M., Hildebrand, J.A., 2007. Temporal separation of blue whale call types on a southern California feeding ground. Anim. Behav. 74 (4), 881-894.

Oleson, E.M., Širović, A., Bayless, A.R., Hildebrand, J.A., 2014. Synchronous seasonal change in fin whale song in the north pacific. Plos One 9 (12), e115678.

Perry, S.L., DeMaster, D.P., Silber, G.K., 1999. The fin whale. Mar. Fish. Rev. 1 (61), 44-51.

Raven webpage. 〈http://www.birds.cornell.edu/brp/raven/RavenVersions.html〉.

Rebull, O.G., Cusí, J.D., Fernández, M.R., Muset, J.G., 2006. Tracking fin whale calls offshore the galicia margin, north east atlantic ocean. J. Acoust. Soc. Am. 120 (4), 2077-2085.

Reilly, S.B., Bannister, J.L., Best, P.B., Brown, M., Brownell Jr., P.J., Robert, L., Butterworth Doug S Clapham, Cooke, J., Donovan, G.P., Urbán, J., Zerbini, A.N., 2008. Balaenoptera musculus ssp. intermedia. (errata version published in 2016). The IUCN Red List of Threatened Species 2008.

RESIF. 〈http://seismology.resif.fr〉.

Rhianne, W., Gavrilov, A.N., McCauley, R.D., 2017. Spot call: A common sound from an unidentified great whale in australian temperate waters. J. Acoust. Soc. Am. 142 (2), EL231-EL236.

Rhum-rum dataset. 〈http://dx.doi.org/10.15778/RESIF.YV2011〉.

RHUM-RUM web page. 〈http://www.rhum-rum.net〉.

Rice, D.W., 1998. Marine Mammals of the World: Systematics and Distribution. Allen Press.

Samaran, F., Adam, O., Guinet, C., 2010a. Discovery of a mid-latitude sympatric area for two southern hemisphere blue whale subspecies. Endanger. Species Res. 12 (08).

Samaran, F., Guinet, C., Adam, O., Motsch, J.-F., Cansi, Y., 2010b. Source level estimation of two blue whale subspecies in southwestern indian ocean. J. Acoust. Soc. Am. 127 (6), 3800-3808.

Samaran, F., Stafford, K.M., Branch, T.A., Gedamke, J., Royer, J.-Y., Dziak, R., Guinet, C., 2013. Seasonal and geographic variation of southern blue whale subspecies in the indian ocean. PLoS ONE, Public Libr. Sci. 8 (8), e71561.

Schmid, F., Schlindwein, V., Koulakov, I., Plötz, A., Scholz, J.-R., 2017. Magma plumbing system and seismicity of an active mid-ocean ridge volcano. Sci. Rep. 7, 42949. http://dx.doi.org/10.1038/srep42949.

Širović, A., 2006. Blue and fin whale acoustics and ecology off Antarctic Peninsula (Ph.D. thesis). University of California, San Diego.

Širović, A., Hildebrand, J.A., Wiggins, S.M., McDonald, M.A., Moore, S.E., Thiele, D., 2004. Seasonality of blue and fin whale calls and the influence of sea ice in the western antarctic peninsula. Deep Sea Res. Part II: Top. Stud. Oceanogr. 51 (17), 2327-2344.

Širović, A., Hildebrand, J.A., Wiggins, S.M., Thiele, D., 2009. Blue and fin whale acoustic presence around Antarctica during 2003 and 2004. Mar. Mamm. Sci. 25 (1), 125-136.

Širović, A., Oleson, E.M., Buccowich, J., Rice, A., Bayless, A.r , 2017. Fin whale song variability in southern california and the gulf of california. Sci. Rep. 7.

Socheleau, F.-X., Leroy, E., Carvallo Pecci, A., Samaran, F., Bonnel, J., Royer, J.-Y., 2015. Automated detection of antarctic blue whale calls. J. Acoust. Soc. Am. 138 (5), 3105-3117.

Stafford, K., Citta, J.J., Moore, S.E., Daher, M., George, J.E., 2009. Environmental correlates of blue and fin whale call detections in the north pacific ocean from 1997 to 2002. Mar. Ecol.-Progress. Ser. 395, 37-53 (12).

Stafford, K.M., Bohnenstiehl, D.R., Tolstoy, M., Chapp, M., Mellinger, D.K., Moore, S.E., 2004. Antarctic-type blue whale calls recorded at low latitudes in the indian and eastern pacific oceans. Deep Sea Res. Part I: Oceanogr. Res. Pap. 51 (10), 1337-1346.

Stafford, K.M., Chapp, E., Bohnenstiel, D.R., Tolstoy, M., 2011. Seasonal detection of three types of "pygmy" blue whale calls in the indian ocean. Mar. Mamm. Sci. 27 (4), 828-840.

Stähler, S.C., Sigloch, K., Hosseini, K., Crawford, W.C., Barruol, G., Schmidt-Aursch, M.C., Tsekhmistrenko, M., Scholz, J.-R., Mazzullo, A., Deen, M., 2016. Performance report of the RHUM-RUM ocean bottom seismometer network around La Réunion, western Indian Ocean. Adv. Geosci. 41, 43-63.

Thomisch, K., Boebel, O., Clark, C.W., Hagen, W., Spiesecke, S., Zitterbart, D.P., Van Opzeeland, I., 2016. Spatio-temporal patterns in acoustic presence and distribution of Antarctic blue whales Balaenoptera musculus intermedia in the Weddell Sea. Endanger. Species Res. 30, 239-253.

Thompson, P.O., Findley, L.T., Vidal, O., 1990. 20-hz pulses and other vocalizations of fin whales, Balaenoptera physalus, in the gulf of california, mexico. J. Acoust. Soc. Am. 88 (S1) (S5-S5).

Trudelle, L., Cerchio, S., Zerbini, A.N., Geyer, Y., Mayer, F.-X., Jung, J.-L., Hervé, M.R., Pous, S., Sallée, J.-B., Rosenbaum, H.C., Adam, O., Charrassin, J.-B., 2016. Influence of environmental parameters on movements and habitat utilization of humpback whales (Megaptera novaeangliae) in the madagascar breeding ground. R. Soc. Open Sci. 3 (12).

Tsang-Hin-Sun, E., Royer, J.-Y., Leroy, E.C., 2015. Low-frequency sound level in the southern Indian Ocean. J. Acoust. Soc. Am. 138 (6), 3439-3446.

Wafar, M., Venkataraman, K., Ingole, B., Ajmal Khan, S., LokaBharathi, P., 2011. State of knowledge of coastal and marine biodiversity of indian ocean countries. PLOS ONE 6, 1-12 (01).

Watkins, W.A., Tyack, P., Moore, K.E., Bird, J.E., 1987. The 20-hz signals of finback whales (Balaenoptera physalus). J. Acoust. Soc. Am. 82 (6), 1901-1912.

Weirathmueller, M.J., Stafford, K.M., Wilcock, W.S.D., Hilmo, R.S., Dziak, R.P., Tréhu, A.M., 2017. Spatial and temporal trends in fin whale vocalizations recorded in the ne pacific ocean between 2003-2013. PLoS ONE 12 (10), e0186127.

Wilcock, W.S.D., 2012. Tracking fin whales in the northeast pacific ocean with a seafloor seismic network. J. Acoust. Soc. Am. 132 (4), 2408-2419. 